\title{
THE GENDERED CONSEQUENCES OF PARENTAL SEPARATION FOR PARENTS' AND CHILDREN'S TIME INVESTMENTS: A LONGITUDINAL STUDY ${ }^{1}$
}

\author{
Tomás Cano* \& Pablo Gracia \\ Goethe University of Frankfurt \& Trinity College Dublin
}

\begin{abstract}
Parental separation has negative consequences for child development, parental well-being, and gender equality, partially due to changes in time use. However, there is a lack of longitudinal studies on how parental separation affects parents' and children's time use. Using unique Australian longitudinal time-diary data across six waves, this study examines how parental separation affects parent-child time and children's time across activity types. Results show that separation does not alter parent-child total time, but it leads to a massive increase of gender inequality: mother-child time doubles, two-parent time declines by three, and father-child time remains low. After separation, children reduce time in educational activities (e.g., studying, reading) and sharply increase their time in unstructured activities (e.g., TV, videogames, mobile phones). Yet, separation effects on children's time use are twice as large for boys than for girls, with gender gaps in unstructured time increasing with years since separation. Mother-child time returns to similar pre-separation levels, but only four years after separation. Results are robust to different panel regression modelling strategies.
\end{abstract}

\section{Keywords:}

Divorce, time-use, life course, social stratification, gender, child development

\section{${ }^{\star}$ Corresponding author: tomascl010@gmail.com}

\footnotetext{
${ }^{1}$ We gratefully acknowledge funding support from the research project CSO2016-80484-R (funded by the Spanish Ministry of Science; PIs: Pau Baizán and Clara Cortina) and project 'Social Inequalities in Girls' and Boys' Daily Activities and Skills Accumulation' (funded by Trinity College Dublin). Previous versions of the study were presented at Trinity College Dublin (Dublin, Ireland; 2019), the Economic and Social Research Institute (Dublin, Ireland; 2019), the Goethe University of Frankfurt (Frankfurt, Germany; 2019), the University of Rotterdam (Rotterdam, The Netherlands; September 2019) and at the European Consortium for Sociological Research Conference (Lausanne, Switzerland; September 2019). We thank participants at these events and, in particular, Martin O'Flaherty and Lena Scherf for their valuable comments and assistance on our study
} 


\section{INTRODUCTION}

The second half of the $20^{\text {th }}$ century saw a dramatic surge of parental separations, a change that has raised concerns among policy makers and researchers about the risks of separation for both parents' and children's well-being (OECD, 2018) ${ }^{2}$. A wealth of research on divorce concludes that parental separation has negative causal effects on mothers' career outcomes, fathers' involvement, and child development (Kreyenfeld and Trappe, 2020; McLanahan et al., 2014). However, the mechanisms driving the causal links between separation and declining well-being are poorly understood. Changes in disposable money and time have been suggested as two key mechanisms through which parental separation affects parents and children (Amato 1993; Carlson, 2006). This study focuses on the effect of parental separation on both parents' and children's time investments.

The relevance of studying the effect of parental separation on time use is twofold. First, time investments are essential inputs for child development (Authors; Hsin, 2009). If parental separation affects children's activities and their time with parents, then analyzing how separation influences parent-child time and children's time use is of central importance to understand differences in child development between two-parent and single-parent families. Second, single parenthood leads mothers to significant declines in income levels and reduced career progression to well-paid jobs (Brady et al., 2017; Mortelmans, 2020). One key explanation of the increasing gender gaps in economic well-being after separation is that women experience disproportionate caregiving obligations after divorce (Kreyenfeld and Trappe, 2020). Thus, by establishing precisely how parent-child time changes after separation, researchers can also offer robust evidence of an important determinant of gender inequalities in well-being after separation.

Given the relevance of time investments for both children's and parents' well-being, several studies analyzed how parental time varies by family structure. Research provides mixed results. Some

\footnotetext{
${ }^{2}$ Throughout the paper we use divorce, separation or union dissolution as interchangeable synonyms.
} 
studies found that single mothers spend more time in childcare than partnered parents (Pepin, Sayer and Casper, 2018), while other studies did not find sizeable differences in childcare time between single and partnered mothers (Craig and Mullan 2012). Shifting the perspective and looking at time investments from the children's point of view, Kalil et al. (2014) found that children in single-mother families receive less total parental time than those children in two-parent households. However, this literature has two limitations. First, previous studies were based on cross-sectional data, using a research design that cannot capture the effect of parental separation on time investments due to an empirical design that does not control for omitted variable bias. As Pepin et al. (2018: 128) concluded, "an ideal dataset would be longitudinal and would capture time in activities". Second, scholars have tended to focus on "what parents do" (Craig and Mullan 2012; Pepin et al., 2018) or "what children get” (Kalil et al., 2014; Carlson and Berger, 2013). Yet, as children grow and enter adolescence, a key question for child development becomes "what children do". This study fills these important knowledge gaps in the sociological literature.

Our study makes three relevant contributions to the sociological literatures on time use, gender, family structure, and child development. First, we use high-quality longitudinal time-diary data collected bi-annually from parents and children during a 10-years period, which contain detailed information on both total parent-child time and children's time across activity types. This contrasts with previous studies using cross-sectional time-use data and studies based on stylized, coarse measures of time or contact (Cheadle et al. 2010). Using cohort panel data allows us to observe changes in children's and parents' life-course trajectories of time investments before and after parental separation. Similarly, we implement child fixed-effect regressions that control for unobservable factors that may otherwise bias the results. Therefore, instead of comparing time investments across family structures, we capture the effect of separation on time investments using a life-course approach that allows us to capture changes in time use after separation in the short and long term. 
Second, we not only analyze the effect of separation on parental time investments, but also on children's own time investments. Our focus on children's time use is important for the literature, as recent evidence shows that children's own time investments, at a certain age, become more relevant for child development than parental time investments (Del Boca et al., 2017). This gap in knowledge is particularly surprising given the well-documented relevance of children's time investments across activity types for their future development (Authors; Hsin, 2009).

Third, we analyze whether there is heterogeneity by child gender in the effect of separation on children's time use. Recent evidence shows that growing up in a single-parent family has particularly negative effects on boys relative to girls (Chetty et al., 2020). Yet, the factors that may lead boys from single-mother families to perform worse than girls in education or the labor market are poorly understood. One plausible explanation is the potential heterogenous effects of separation on time investments for boys and girls. For example, boys and girls may change their daily routines differently after separation, leading to gendered processes in their leisure or study habits with direct developmental implications. Also, if father-son time is greater than mother-son time, and fathers typically leave the house after separation, boys may be losing more total parental time than girls after divorce. Our study helps answering this sociological puzzle.

Overall, this study is -to our knowledge- the first longitudinal analysis of how parental separation affects the quantity of parents' time invested on their children, and the type of activities "children do" on their own. To accomplish this, we use six waves of high-quality, time-diary, cohort panel data from the Longitudinal Study of Australian Children (LSAC) survey.

\section{Theoretical Framework}

To study the effects of parental separation on parental and children's time investments we consider both the quantity (i.e., total) and quality (type) of this time. Regarding the quantity of time, previous 
studies found a positive effect of parents' total time on child development, including mother-child time (Del Bono et al., 2016), father-child time (Authors) and both-parent time (Fiorini and Keane, 2014). Yet, parent-child time also adds high pressure and demands among parents, especially among mothers, as they spend more time caring for children than fathers, despite a narrowing gender gap in recent years (Bianchi et al., 2006; Craig et al 2006). As for the quality of time, the specific activities in which children spend time are essential for their well-being. For example, children's time spent doing homework or reading books is comparatively more productive for their cognitive development than their time in unstructured activities such as watching TV (Authors; Wight et al. 2009).

We examine two components of time: (a) parental time and (b) children's time. First, parental time investments (i.e., parent-child's quantity of shared time) comprise four categories: father-child time, mother-child time, two-parent time, and time alone without parents. In our measures of motherchild, father-child, and no-parent time, no other adult is present. The quantity of time each parent spends alone with the child indicates parental responsibility and demands, as this care work cannot be shared or avoided; the child's responsibility rests upon the parent. While there is a vast literature on father-child contact after separation (Cheadle et al., 2010; Kalmijn, 2016) we examine how parental separation redistributes total parental time between mother-child, father-child, and two-parent time. Regarding time without any parent (time alone), we capture the time in which the child is without parents and alone, a potential pathway to lowered child development via feelings of loneliness or declines in mental health and well-being (Fujiwara et al., 2018). Unlike previous studies on divorce, which only examined paternal and maternal contact, we simultaneously address changes across all types of parental time (and lack of) before, during and after separation.

Second, we look at children's time investments, where we distinguish between two categories of time: children's time in educational activities and children's time in unstructured activities. Children's educational time includes activities like reading, doing sports or cultural activities, among 
others. Children's unstructured time includes activities like playing video games, watching TV, or nonschool-related internet browsing. We select these activities because they are often shaping heterogeneous pathways in the process of boosting (i.e. educational time) or lowering (i.e. unstructured time) child cognitive development (Authors). When analysing the effect of separation on children's own time investments across activity types, we do not consider if children were with their parents, someone else, or alone. We do it in this way because, as children grow up, what matters more for their development is what they do (e.g., playing video games or reading) more than who they are with during these activities (Del Boca et al., 2017).

\section{Parental Time Investments}

Logically, the quantity of time the child spends with two parents simultaneously will suffer a significant decline after separation. Now, the question is whether parents in different-sex couples compensate for the decline of two-parent time, how that compensation is redistributed between mother and father, and how compensation evolves over the child's life course. It could be that the child gains more parental time after separation, just that the time is distributed differently between mother and father. That would be the case if, for example, mother-child and father-child time increases more than two-parent time declines. This question remain unexplored in the literature.

Studies have shown that parental separation processes and time-use patterns are strongly gendered. 'Gender-roles' theories argue that gendered social norms and everyday individuals' interactions lead women to be more involved in childcare than men in heterosexual couples, with women being more focused on time-consuming and emotionally absorbing activities (Hays 1996; West and Zimmerman 1987). Even if single mothers tend to experience time poverty and high stress while mothering (Haux and Platt 2020; Meier et al. 2016), contemporary gender ideologies still place the 
responsibility of childcare as a fundamental component of women's work (Glenn et al. 2016). This might indicate a significant compensatory increase in mother-child time after separation.

Couple's transition from living together to separation might induce changes in parental identities, particularly for fathers. Identity theory, rooted in symbolic interactionism, separates between statuses and roles (Stryker, 1968). While statuses refer to social positions, roles refer to the behaviours adscripted to each status. This theory distinguishes between salience of each of the possible roles attached to each status, which might be exacerbated or mitigated by the individual depending on a context or situation (Goffman, 1976). Fatherhood is an example of a status with two clear roles attached to it: provider and caregiver. When couples separate, ambiguity over fathers' roles tends to increase, possibly leading to declines in childcare time investments (Rane and McBride, 2000). Another important mechanism behind possible changes in father-child time after separation is time availability (Coverman, 1985). In Australia, mothers take the child's custody in nine out of ten separated couples, where fathers move out from home: this imposes physical, temporal, and monetary limits for fathers' childcare time investments (e.g., commuting costs, finding a new house) (Smyth and Chisholm 2017). These arguments lead to the expectation that father-child time will decline after separation.

The amount of time that children spend without any parent should not lead to important changes after parental separation. Pasteels and Bastaits (2020) found that children who experienced parental separation do not differ in their feelings of loneliness compared to children in two-parent families, and loneliness is an emotion associated with an increase in time alone (Van Roeckel et al., 2015). We assume that, if it is true that mothers make a strong effort to compensate for the loss of resources and fathers' absence by increasing their time with children after separation, this should neutralize children's potential risks of spending time alone when divorce occurs.

Previous studies analysed post-separation levels of parent-child contact and involvement, but without using a longitudinal time-use approach. Using a growth curve mixture to model trajectories of 
father-child contact after dissolution in the US, Cheadle et al. (2010) found that about two-fifth of fathers maintain high levels of contact after divorce, while one-fifth of fathers became largely absent. Although father-child contact after divorce has increased over recent years (Westphal et al. 2014) and "new" fathers are increasingly gender egalitarian (Authors), most studies suggest that father-child time declines after separation (Furstenberg et al. 1983; Koppen et al. 2018; Pardo et al. 2019; Carlson 2006). Evidence for mothers is mixed. A study using fixed-effects models with US data found that partnered mothers are more involved in the child's schooling activities and shared activities at home, compared to single mothers (Ressler et al. 2016). By contrast, a longitudinal study using German data found that mothers' involvement remains quite stable after separation (Gratz 2017). Cross-sectional time-diary studies with accurate time-use data provide inconclusive results too. While an Australia study found that single and partnered mothers spend similar amounts of time with children (Craig and Mullan 2012), a US study found single mothers to spend more time with children than partnered mothers (Kalil et al. 2014). Overall, drawing on our previous theoretical assumptions, we expect the following: Hypothesis 1 - Parental separation leads to a decline of father-child and two-parent time, but an increase of mother-child time, without altering the child's time alone.

\section{Children's Time Investments}

Several theoretical explanations indicate that parental separation might alter children's time across activity types. The 'parental resource perspective' (Coleman 1988) and the 'family investment model' (Astone and Mclanahan 1991) suggest that separation can harm family resources by reducing money (e.g. relocation costs, new expenses) and time (e.g. commuting costs for the absent parent, new job demands, new family obligations) (Amato 1993; Carlson 2006). Declines in parental socio-economic resources should also reduce the time parents can invest in managing or supervising educational activities (e.g., homework, private lessons), as opposed to unstructured activities (e.g., screen-based 
time), which are economically less costly and subject to increase when parental presence at home declines. Therefore, separation might discourage children's time in educational activities, as these activities crucially depend on parents' time availability, persistence and resources to invest in children (Lareau 2011).

Parental separation can also increase stress levels within families and this in turn may contribute to changes in children's own activities. The 'divorce stress-adjustment perspective' (Amato 1993) suggests that during the process of separation, parents and children experience higher stress levels, a reacting condition linked to lower levels of psychological well-being, life satisfaction, and increase in conflict. A significant group of parents and children experience higher levels of stress during the process of marital breakup (Booth and Amato 1991; Harkonen 2017). For parents, stress can lower energy, capacity and self-efficacy to supervise children and to engage in positive parenting (Kiernan and Huerta, 2008; Haux and Platt 2020). For children, lower levels of psychological wellbeing or more family conflicts at home might induce to higher temptation of participating in unstructured leisure activities, like watching TV or engaging in social media. Overall, we expect the following: Hypothesis 2-Parental separation leads to an increase of child time in unstructured activities, and a reduction of child time in educational activities.

\section{Heterogeneous Effects by Child Gender}

Previous research suggests that child gender can moderate the effect of parental separation for both parents' and children's time investments. First, parental time investments differ by child gender. Across countries, mothers have been found to spend more time with daughters and fathers with sons, reflecting gendered socialization processes (Raley and Bianchi 2006). Same-sex preference responds to higher internal satisfaction levels, peer-pressure, social expectations, and comparative advantage (Bonke and Esping-Andersen 2011; Harris and Morgan 1991; Lundberg 2005). Therefore, if most 
single-parent families are headed by mothers, increases in mother-child time after separation might favour daughters compared to sons. By contrast, if father-son time is greater than father-daughter time, we might expect a greater decline in paternal time received by sons, as fathers typically leave the house after separation. Also, if boys experience a greater decline in paternal time, they might also experience a greater increase in solo time than girls, as sons have more total parental time to lose. Father-child time has been found to experience sharper declines for daughters after divorce, compared to sons (Bastaits et al. 2015; Gratz 2017). Accordingly, we expect the following: Hypothesis $3 a$-The increase of mother-child time after separation is greater for girls than for boys, and the decline in father-child time is greater for boys than for girls.

Second, children's time investments are also gendered. Time-use research shows that boys spend more time in unstructured activities like screen-based leisure time, while girls spend more time in educational activities (Authors; Wight et al. 2009). Parental separation might amplify these gender differences in children's time investments. While studies have often found small gender differences in how parental separation affects child development (Amato 2010), paternal absence was found to induce boys to higher aggressiveness or anti-school attitudes, with boys showing greater difficulties than girls in adjusting to parental divorce in new family arrangements, often in single-mother families (Hetherington and Stanley-Hagan 1997; Rutter 1987; Legewie and DiPrete 2012). Ethnographic research reveals that adolescent girls - under specific processes of family change- embrace a feminine identity based upon studying hard, being attentive and caring for others (Epstein 1998). By contrast, boys might demonstrate a masculine identity in changing social or family processes by "taking pride in their lack of academic effort" (Morris 2008, 736). These exaltations of gender-role behaviours can be increased via stress induced by parental separation. Therefore, we expect the following: Hypothesis 3b-After separation, boys show a sharper increase in time spent in unstructured activities and a greater decline in time spent in educational activities than girls. 


\section{A Life-Course Approach}

Do the effects of parental separation on parents' and children's time investments increase, decrease or persist over the years? This question remains unanswered. Previous studies on the effect of separation on income or mental health show strong negative effects in the short run, but with a recovery to preseparation levels after around one year after separation (Booth and Amato 1991; Leopold and Kalmijn 2016; Leopold, 2018). Such timing of levelling up income and stress to pre-separation levels might be paralleled in terms of time investments.

Two-parent time might recover after the years since separation. One possibility is that former partners reduce their conflict with the years, meaning that they might share some moments of the week with children. Also, after several years since separation occurred, parents might start new partnerships, with whom sharing childcare time would be possible, with the entrance of new paternal and maternal figures that play a new role in family processes (Kalmijn et al., 2019). As a result, maternal time might steadily decline to get closer to pre-separation levels, in parallel with a recovery of two-parent time over the years since separation. We expect the following: Hypothesis $4 a-$ After the years since separation, there is an increasing recovery in two-parent time and a steady reduction of maternal time, getting closer to pre-separation levels.

Previous studies have not analysed both the short and long-term effects of parental separation in children's daily activities. The most important shocks in resources, family stress and daily routines after separation happen in the short run (e.g., Booth and Amato 1991). After such initial shock, parents and children tend to stabilize their material uncertainty and emotional concerns, instead of getting locked in a persistent negative state. Therefore, we expect the following: Hypothesis (4b) The effects of parental separation on children's educational and unstructured activities are strong when separation occurs (short-run effect), but it stabilizes in the subsequent years (long-term effects). 


\section{METHOD}

\section{Data and Sample}

We use data from the Longitudinal Study of Australian Children (LSAC), a biennial survey that started in 2004 including two cohorts of approximately 5,000 Australian children each, one born in 2000 ("Kindergarten Cohort") and another one born in 2004 ("Birth Cohort") (Australian Institute of Family Studies 2002). The LSAC is internationally unique in that it offers rich longitudinal time-diary data for each interview year. Time-diary data cover individuals' daily activities on a 24-hours framework, providing more reliable and less biased data than stylized questions asking "how often" respondents engage in activities (Bianchi et al. 2006; Kan 2008; Fisher et al. 2012).

We restricted our analyses to six waves of the 'Kindergarten Cohort', which covers information from age 4 (2004) to age 14 (2014). Time diaries in the LSAC were designed to change over time and are therefore adapted to children's developmental processes. In waves 1-3 (ages 4-8), as children were very young, parents filled out two "light diaries" (Hofferth et al. 1997). These light diaries split the day into 15-minutes time intervals, with a total of 96 time slots. In waves 4-6 (ages 10-14), time diaries were no longer filled out by parents, and instead children filled the diaries themselves. In waves 4-6, children wrote down what they were doing during the 24 hours in a structured temporal sequence. The day after the interview, interviewers coded information provided by children into a pre-defined list of activities and collected information about who was the child with and where ${ }^{3}$. The 'Kindergarten Cohort' contains time-diary information on 'with who' children spent time across all six waves (e.g., alone, with father, with mother or both parents) (Corey et al. 2014; Mullan 2014).

We restrict our analysis to weekdays. While waves 1-3 included two time-diaries per child (one for weekdays and one for weekends), waves 4-6 only included one diary per child, where weekends

\footnotetext{
${ }^{3}$ An example of the LSAC time diaries in waves 1-3 can be seen here: http://data.growingupinaustralia.gov.au/studyqns/wavelqns/TUD14.pdf. For waves 3-6, see: https://growingupinaustralia.gov.au/sites/default/files/tp13.pdf pp. 21-45).
} 
were significantly underrepresented (Mullan 2014, 15). This may hamper comparability across waves. Therefore, by focusing only on weekdays, our analyses reduce this source of bias across waves, as the number of weekdays diaries is stable across all waves. While weekend diaries are relevant too, studying children's daily routines during weekdays is crucial, as it is during weekdays when many children engage in regular sets of routines that are essential for their subsequent development (Fiorini and Keane 2014). Most time-diaries were collected between mid-March and the end of September to skip summer school holidays in Australia (December-January).

Our sample included all diaries collected by children who in Wave 1 (age 4) were living with two biological different-sex parents. We excluded diary observations with missing information in living arrangements $(n=3$ diaries), mother's or father's level of education $(n=413$ diaries $)$, transitioning to a single-parent house due to parental death $(n=67$ diaries), those who entered the survey already with separated parents or living in other arrangements than two biological parents $(n=$ 2,713 diaries), and those who mistakenly had duplicate diaries ( $n=35$ diaries). After these exclusions, we ended up with a total of 14,862 observations from 3,719 children.

Analyses included two subsamples. The separation sample contains all children who experienced a transition from living with two parents to living with just one parent $(n=2,054$ observations from 505 children). The partnered sample includes all children observed in two-parent homes across the 6 waves ( $n=12,808$ observations from 3,214 children). Keeping the 'partnered sample' in our analyses has two main advantages: (a) experiencing divorce is a selective life-course transition (i.e., the lower-educated separate more than the higher-educated) and so keeping both samples allows us to observe selective differences between families who experience separation and those who do not; (b) by keeping the partnered sample we increase the final sample size, allowing for better effect's estimations in general, and for an age effect estimation in particular (Leopold 2018). 


\section{Dependent Variables: Measures of Time Investments}

The LSAC allows us to examine both the quantity (e.g., parent-child total daily minutes) and content (e.g., reading/studying) of time. Our dependent variables are constructed by following a comparable harmonization across the six waves of study, drawing on previous studies and reports (see Table A1) (Authors; Corey et al. 2014; Mullan 2014). We use a total of six dependent variables. Four dependent variables capture parental time investments: (1) Two-parent time: child was with mother and father together; (2) Mother-child time: child was with mother and without father present; (3) Father-child time: child was with father and without mother present; (4) Time alone: child was without any parent or other person present ${ }^{4}$. The other two dependent variables capture children's time investments, which measure child total daily minutes allocated to two groups of relevant activities, irrespective of with whom these activities occur: (5) Educational time includes cognitively stimulating activities performed outside school (e.g., reading, studying, doing puzzles, playing music, going to libraries); and (6) Unstructured leisure time includes non-structured leisure activities (e.g., watching TV, non-structured play, mobile phone texting). ${ }^{5,6}$

\section{Independent Variable: Parental Separation}

Our independent variable is parental separation. We identify parental separation by a change in the child's household composition from "living with two biological parents" to not "living with two biological parents" (in $95 \%$ of the cases the first transition is from living with two different-sex

\footnotetext{
${ }^{4}$ Diaries did not distinguish between copresence with social or biological father and social or biological mother; only $1.3 \%$ of the observations in the total sample ( $9.2 \%$ in the divorced sample) lived with a step-parent (normally, a step-father).

${ }^{5}$ We multiplied the resulting number by 1 in each of the slots marked with our activities of interest. In waves 1-3, we calculated time by multiplying each of the 96 diary slots marked with one of our activities of interest by 15 . In waves 4-6, where diaries were not divided into pre-defined number of slots, we first used the difference between activities' end-times and activities' start-times to calculate time duration within the defined sequences of starting activity hours.

${ }^{6}$ As in previous research (Authors), when multiple activities were carried on at the same time, we divided the number of activities by the specified time. For example, if the child reported to be doing homework and watching TV between $4 \mathrm{pm}$ and $5 \mathrm{pm}$, we counted 30 minutes to educational activities and 30 minutes to unstructured leisure.
} 
biological parents to living only with the biological mother, and 5\% transit to living only with the biological father).

To capture temporal dynamics of parental separation on time investments (i.e., short- and longterm effects), we split our independent variables in two: (a) a dummy variable changing from 0 (observations without separation) to 1 (with separation), and (b) a categorical variable identifying time-use before and after separation, where 0 is the first observation after separation. To prevent cells with low number of cases, we recode the duration categorical variable into five categories of time before and after separation: 10 to 8; 6 to 4; and 2 years before separation; the first observed year after separation (0); 2; and 4 or more years after separation. As in Leopold (2018), observations of the 'partnered sample' are set in the reference category (i.e., 10 to 8 years before divorce/separation).

\section{Control and Moderator Variables}

We consider multiple covariates that are potential confounders in the effect of parental separation on time investments: State (categorical), Siblings at home (dummy); Language spoken at home (English or not: dummy); Re-partnering (whether a non-biological parent entered the home after separation); Father's/mother's education (University degree or not); Child age, as a categorical variable to avoid collinearity with duration before or after separation (ages: 4, 6, 8, 10, 12 and 14); Father's/mother's SES, based on four categories recoded from the Australian and New Zealand Standard Classification of Occupations (ANZSCO) (Australian Bureau of Statistics 2013): (1) Managers and professionals;

(2) Intermediate class (i.e., skilled technicians, non-manual works in sales, commerce and administration); (3) Working class (i.e., production workers, routine workers in industry or service); No occupation (i.e., unemployed or inactive). Finally, child's sex (female/male at birth) is our moderator variable to investigate gender differences in the effects of separation on time investments. 
[Table 1 around here]

Table 1 shows the study measures' means and standard deviations for the whole sample, the partnered sample and the separated sample. Besides providing descriptive evidence on the dependent variables by family structure, Table 1 shows that children in separated families are overrepresented in socioeconomically disadvantaged households, especially when looking at fathers' characteristics. These distributions indicate the relevance of controlling for unobservable factors driving both the propensity of family instability and the child's own time investments.

\section{Empirical Strategy}

We start with the following linear model for repeated observations nested within children:

$$
f\left(T_{i t}\right)=\alpha+\beta_{1} \boldsymbol{F B}_{i t}+\beta_{2} \boldsymbol{X}_{i t}+\beta_{3} \boldsymbol{G}_{i t}+\eta_{i}+e_{i t}
$$

Where $T$ is time (alone, with father, mother, both parents, and across activity types) of child $I$ in year $t$, and $\alpha$ is the intercept. $\boldsymbol{F B}$ contains a dummy and a continuous indicator of parental union dissolution. $\beta_{1}$ indexes the coefficients of main interest to test our working hypotheses. $\boldsymbol{X}$ is a vector of timechanging control variables, while $\boldsymbol{G}$ is child's sex, our only time-constant variable. $\beta_{2}$ and $\beta_{3}$ are the coefficients of both kinds of control variables; $\eta$ represents person specific time-constant unobserved factors affecting selection into divorce and time use; $e$ is the random disturbance across $i$ and $t$.

We first we use Random-Effects (RE) generalized least squared regressions (GLS). RandomEffects models are especially suitable for our research because they allow us to obtain main effects of time-invariant variables, and our moderator variable is time-invariant (i.e., child's sex). This is particularly relevant, as pre-divorce time-use of boys and girls may differ (Mencarini et al. 2019). 
However, Random-Effects GLS models impose the strong assumption that $e_{i t}$ and $\eta_{\mathrm{i}}$ are not correlated with divorce and time investments (Allison 1994). Also, the probability of divorce could be associated with time-use through time-constant unobservable factors, leading to selection bias.

We further estimate Fixed-Effects models (FE). FE models are more robust than RE models and they partially avoid self-selection bias of time-constant unobservable factors (Wooldridge 2010). The FE model takes the form of:

$$
f\left(T^{*}{ }_{i t}\right)=\beta_{2} \boldsymbol{F} \boldsymbol{B}_{i t}+\beta_{3} \boldsymbol{X}^{*}{ }_{i t}+e_{i t}
$$

The robustness of FE models comes at a price: in this equation, $\boldsymbol{G}$ drops because child gender is a timeinvariant variable that cannot be estimated. As noted, $\eta$, because is time-invariant, also drops from the equation. Therefore, the coefficients of interest (i.e., $\beta_{3}$ ) are not affected by any observed (or unobserved) time-invariant factors correlated with $\boldsymbol{F B}$ and $\boldsymbol{T}$. This eliminates selection bias due to time-invariant unobservable factors. In equation (2), $\boldsymbol{T}^{*}{ }_{i t}, \boldsymbol{F B}{ }_{i t}$ and $\boldsymbol{X}^{*}{ }_{i t}$ are the time-variant differences from the individual means. Thus, this model tells us how changes over time in individuals' characteristics affect changes in time use. That is, individuals act as their own statistical adjustment. Although this modelling is not completely free of bias (e.g., time-changing unobserved factors), it accounts for potential bias encountered in the RE models. As put by Amato and Anthony (2014, 373): "Given the impossibility of conducting true experiments, child fixed effects models are one of the best available methods for estimating the causal effect of divorce on children".

We estimated multiple models for each of our six dependent variables by firstly estimating the short-term separation average effects (i.e., with the dummy variable of separation) and, secondly, the long-term separation effects (i.e., with the categorical variable of separation duration). As indicated, 
we test our four hypotheses using both FE and RE models. We finally conduct several sensitivity analyses.

\section{FINDINGS}

\section{Parental Time Investments}

Figure 1 and Figure 2 present the first set of regression models on the effect of separation on children's time with mother, father, two parents and alone. Figure 1 shows the average effect of separation (presented as regression coefficients). Figure 2 shows the long-term effect of separation across the years before and after the event (presented as predicted values). Panel A shows the results for the Random-Effect regressions, while Panel B illustrates the Fixed-Effects regressions. The full models are shown in Tables A2 and A3.

[Figure 1 around here]

Figure 1 (Panel A) shows that separation is strongly associated with changes in parent-child time. Consistent with Hypothesis 1, we observe a sharp increase in mother-child time after separation, accounting for 107 daily minutes $(p<0.001)$. This occurs at the cost of two-parent time, which shows a sharp decline of 96 daily minutes $(p<0.001)$. By contrast, father-child time remains unchanged after separation, being reduced only by 5 minutes per day. Time alone experiences a small decline of 14 minutes. Panels A and B (Random- and Fixed-Effects respectively), show similar results.

[Figure 2 around here] 
Figure 2 shows relevant variations in the long-run effects of separation on parent-child time. Panel A (Random-Effects) shows that the strong positive effect of separation on mother-child time is concentrated in the first observation after divorce (i.e., year 0 in the graph), with major increases of nearly two hours per day. Mother-child time takes four years until reaching almost the same predivorce levels. By contrast, father-child time barely changes with separation, with a slow, unsubstantial and non-significant decline over the years. Two-parent time decreases dramatically in the immediate separation year, but it increases in the following years. Finally, time alone returns to pre-divorce levels after two years since separation, but with minor changes. Again, Panels A and B (Fixed- and RandomEffects) show similar results.

\section{Children's Time Investments}

Figure 3 and Figure 4 show the effects of parental separation on children's time in educational activities and unstructured leisure. Figure 3 presents the average effects models and Figure 4 the long-term effects, with the two figures showing both Random- and Fixed-Effects models. Results are generally in line with Hypothesis 2, particularly for unstructured leisure activities. Figure 3 (Panel A) shows that parental separation leads children to increase their unstructured leisure time by 17 minutes a day $(p<$ $0.001)$ and to a smaller decrease of 8 daily minutes in educational activities. The results of Randomand Fixed-Effects models (Panels A and B respectively) show again similar results. In Figure 4, we observe a negative trend in children's time on educational activities after parental separation and a positive trend on unstructured leisure activities, but such a trend stabilizes two years after divorce.

[Figure $3 \& 4$, around here] 


\section{Heterogeneous Effects by Child Gender}

Figure 5 illustrates the Random-Effects models to test Hypothesis 3. Panel A shows average effects of separation for all study six dependent variables estimated separately for the subsample of boys and the subsample of girls. Panel B presents the long-term effects of separation on the same six dependent variables, interacting the variable 'child sex' with 'time since divorce'. For reasons of space, in this section we only report results from Random-Effects. Results from Fixed-Effects models were consistent with those from Random-Effects (available upon request to authors).

Figure 5 shows results that support Hypothesis 3 in various respects. In Panel A (average separation effects) of Figure 5, we observe that boys, compared to girls, lose more father-child solo time ( $\beta=-9$ versus -2 daily minutes) and more two-parent time ( $\beta=-104$ versus -91 daily minutes). Also, boys' time alone remains stable after divorce, while time alone for girls declines by 24 daily minutes. Regarding activity types, after parental separation, boys increase their time in unstructured leisure activities by 31 daily minutes, while girls increase it by 14 minutes. We see that boys reduce their time in educational activities by 10 daily minutes after separation, with girls reducing their educational time by 5 minutes only. Interestingly, unlike predictions, mother-child solo time increases equally for boys and girls after divorce.

[Figure 5 around here]

In Panel B (long-term effects) of Figure 5 we observe that only boys increase two-parent time before divorce, but gender differences in two-parent time disappear afterward. Two years after separation, boys keep the same levels of father-child solo time and girls drop their father-child solo time, but gender differences in father-child solo time vanish after four years since separation. Gender gaps in unstructured leisure time increase remarkably over the years since separation. Before divorce, 
boys spend 156 daily minutes in unstructured leisure, with girls spending 136 minutes in the same activities (14\% gender gap). Two years after separation, boys spend 182 daily minutes in unstructured leisure and girls 137 (28\% gender gap). After four years since divorce, boys spend 193 daily minutes in unstructured leisure, while girls only 121 minutes (46\% gender gap).

\section{Additional Analyses: Separation Effects across Children's Ages}

We additionally tested if the effect of parental separation on time investments differs across age groups. The older the children are, the less time they spend with parents, and the more time they spend alone and in unstructured leisure or educational activities (Authors; Lareau 2011; Kalil et al. 2012). Although we control for child age, we examined differences across child age transitions as a robustness check, as child age may be a confounder for being correlated with time investments.

We split the main sample into five subsamples of transitions: ages 4-6; ages 6-8; ages 8-10; ages 10-12; ages 12-14. Following Todd and Wolpin (2007), we capture child cumulative processes of learning by calculating the effect of separation on time investments in the five subsamples using five separated Value-added models. Value-added models control for each of the dependent variables at $t-1$. In this way, current time investments depend on previous time investments and previous parental inputs, thus capturing the cumulative dimension of learning across developmental processes.

Table 2 presents the results of the Value-added models ${ }^{7}$. Results confirm the heterogeneous effects of separation on time investments across child age-specific developmental stages. Estimates of parental time investments decrease in magnitude as the child grows up. On the contrary, estimates of children's time investments increase in magnitude as the child grows up. This is coherent with the notion that, as children grow up, they spend less time with parents and more time on their own. Results

\footnotetext{
7 We further conducted Lagged-inputs plus Value-added models for our five child-age subsamples (for details, see Todd and Wolpin, 2007). These results were consistent with the analyses presented in Table 2.
} 
of this additional analysis do not change the conclusions of this study, but they show a more nuanced picture: the younger the child when separation occurs, the larger the effect of divorce on parental time investments; and the older the child, the larger the effect on children's time investments.

[Table 2 around here]

\section{Robustness Checks}

We carried out three final robustness checks (available upon request to authors). First, we replicated our models by including control variables indexing mothers' and fathers' paid work hours. We decided not to include employment status in the main models because they fall into the causal pathway between parental separation and time investments: time devoted to paid work should affect time with children as well as be affected by separation. Therefore, the inclusion of time in paid work could potentially downward our estimates, particularly those of parental investments. However, including employment status of both parents as control variables did not change the conclusions of this study.

Second, we analysed whether the resident parent's re-partnering alters the effects of separation on time use. One fourth of the couples who separate are observed to find a new partner within the period of observation. This might potentially alter our parent-child time estimates. Yet, analyses for a sample excluding children who experienced re-partnering at home after divorce show similar results to those from our main analyses. This would imply that children see their time with both biological parents dropping to nearly zero minutes when separation occurs, while two-parent time with the two biological parents would increases over the years since divorce. Perhaps once tensions associated with marital dissolution fade away, biological parents are willing to spend more time together with their children, as the short-term negative effects of divorce over families' mental health, stress, and conflict vanish after one or two years (e.g., Leopold and Kalmijn 2016). An alternative explanation is that, with 
years since separation, children start to consider new parental figures that are not necessarily residing in the household, but who are sharing time with them and one of their parents. We cannot fully answer this question with our data. Future studies should further examine differences in parent-child time among non-residential biological parents, social parents and stepparents.

Finally, we replicated our analyses separately for waves 1-3 and waves 4-6. We did this final sensitivity test because time-diaries had a change in reporter between waves three and four, being the mother filling out the diary in the first three waves, and the child in subsequent waves. Again, results splitting the analysis by diary's reporter were similar to those shown in our main analyses.

\section{DISCUSSION}

In this study we have provided what is, to our knowledge, the first dynamic study of the effects of parental separation on parental involvement and children's time investments, using high-quality longitudinal time-diary data from Australia. Previous studies focused only on the effect of separation on parent-child contact or parental involvement, often using cross-sectional data. Instead, we present a new life-course approach using panel data and focusing on time use among both parents and children. Our research design - unlike previous related studies- allows us to control for omitted-variable bias, which has been an essential concern within the divorce literature (McLanahan et al. 2013). This study has four main findings.

First, our analyses provide clear evidence of a gendered shift in the composition of parental time after separation: divorce leads to a huge increase of mother-child time, paralleled by a similar decrease of two-parent time. Two-parent time drops from circa 100 minutes a day to nearly zero after divorce. However, these 100 minutes of parental time are not "lost" but reallocated: mothers compensate for such decline by increasing the amount of time they spend alone with their children by 100 minutes a day. Father-child time remains low and virtually unaffected by parental separation. 
These results support our Hypothesis 1, except for paternal time. That father-child time does not change with separation is somehow surprising and against our theoretical predictions and previous studies (Cheadle et al., 2010; Gratz, 2017; Kalmijn, 2015). Our dynamic approach complements the cross-sectional study of Kalil et al. (2014), showing that single mothers do more solo childcare than partnered mothers in the US. We find that, before separation, mothers spend 150 daily minutes of solo time with their children, while fathers spend an average of 50; that is, three times less. These figures are in line with Craig's (2006) cross-sectional study with Australian data from 1997 for different-sex couples with young children. Yet, our dynamic model allows for a causal estimation of the transition from a two-parent to a single-parent family. After separation, the gender gap in parent-child time jumps from three to seven times, with mothers spending 350 daily minutes with children and without their partner, and fathers still spending 50 minutes of time with their children without presence of the partner. Consistent with a "time poverty" perspective (see Pepin et al., 2018; Chatzitheochari and Arber, 2012), we find a dramatic increase of gender inequalities in parental time costs after separation. These inequalities are important in explaining women's disadvantages in their leisure and paid work time after divorce, which are closely linked to inequalities in income and well-being.

Second, we find that parental separation leads to a substantial change in children's own time investments across activity types. We find that for unstructured leisure, as children see an increase of 22 daily minutes (i.e., from 153 minutes a day on average, to 175) and educational activities, as children experience a decrease of 8 daily minutes (i.e., from 202 minutes a day on average, to 192). These results are in line with Hypothesis 2. These findings contribute to debates on how parental separation affects child development (Kim 2011; Harkonen et al. 2017). Studies found that educational activities like reading, playing cognitively stimulating games or structured sports are the most relevant inputs for the child cognitive development (Authors; Fiorini and Keane 2014). On the contrary, child time in unstructured leisure (i.e., TV, smartphone usage, unstructured play) has been found to lead to 
sleep disruptions, socio-emotional problems and health disadvantages (Beyens et al. 2018; Kelly et al. 2019). We argue that these changes in time use should partly drive some of the negative effects of parental separation on child development and well-being. Focusing not only on what parents invest on their children, but also on "what children do", represents a new relevant dimension of study to further understand the consequences of divorce for child development.

Third, our analyses reveal that parental separation has more negative effects on developmental activities among boys than among girls. After separation, boys lose more paternal and two-parent time, while girls reduce their time alone, but not boys. Boys see a relevant decline in their educational time (10 daily minutes) and particularly in unstructured leisure time (i.e., watching TV or playing video games) (31 daily minutes) with effect sizes being twice as large as for girls. These results generally support Hypothesis $3 \mathrm{~b}$. This contributes to growing body of research analysing the underachievement of boys within and outside school (Chetty et al., 2020). Previous studies examined several mechanisms that might explain why boys perform worse at school than girls, including teacher bias (Legewie and DiPrete 2012), gendered behavioural outcomes (DiPrete and Jennings 2012), the role of gender egalitarianism and culture (Guiso et al. 2008) or differential parental investments (Baker and Milligan 2016). Our study contributes to explain potential gendered processes of how separation can impact child development by showing that a decline of developmental time use after divorce affects boys more than girls.

Fourth, we find that the effect of parental separation on parents' and children's time use is temporary, with strong effects in the short run, and with a return to pre-separation levels after 2-4 years, particularly regarding mother-child time. This implies that mothers prevent a long-term process of cumulative disadvantage via increasing levels of "time poverty" or "time lost" beyond two years after separation. However, children's time investments follow a different life-course pattern. The negative effects of separation on children's time use are observed already before divorce, stabilising 
after separation. We speculate that the difference in life-course dynamics between parents' and children's time investments show different mediators in the transmission of disadvantage and compensation of life events. The fact that children's time investments change before separation seems to reflect that children's activities are already affected by parents' conflict prior to separation. Future studies should examine more specifically the reality of parents' and children's daily activities and wellbeing during the years and months prior to separation.

Overall, our study suggests that the disadvantaged development of children in single-parent families compared to those in two-parent families may not come from losing father-child time after separation, which is low before and after separation. The sharp sudden increase of mother-child time after separation, apart from leading to higher levels of maternal responsibility and pressure, may also have important consequences for processes of stress, mental health problems and new daily routines that could mediate the negative effect of divorce on child development. These results have relevant repercussions for policy and practice. For example, investing in policies that help alleviate "time poverty" experienced by mothers just after separation should lead to improvements in both gender equality and child development via declines of stress. These policies can include direct income transfers to single mothers and promoting paternal involvement after separation. Our study further connects to sociological literature on children's gendered socialization processes. If boys' developmental time use is more strongly harmed than girls' after separation, these gendered changes in child time investments might contribute to shape gender-typed developmental processes.

Our study has two caveats that we need to mention. First, the LSAC time-diaries were completed by parents in waves 1-3, using paper-based time-diaries, while in waves 4-6 children filled the diaries electronically via digital tablets, without a pre-coded list of activities. To overcome potential bias in this regard, we excluded activities that are not meaningful to compare over the life course (e.g., breastfeeding, changing nappies), focusing on harmonized measures over time (Mullan 2014). We 
conducted supplementary analyses creating two different subsamples depending on the type of timediary collection, which yielded similar results to those reported in the main analyses. It is important to highlight that all children (in both single and two-parent families) filled the same types of diaries. Second, the LSAC time-diaries - unfortunately- did not allow us to clearly distinguish between biological parents and stepparents when examining 'with who' children spent time. To account for this, we controlled for re-partnering in our analyses, and conducted supplementary analyses with a subsample of children who did not experience re-partnering. These analyses provided equivalent results to our main analyses. We hope future research will be able to capture differences in children's time with different parental figures (i.e. social and biological parents), which will add to a relevant emerging field in the sociological literature (e.g., Kalmijn et al 2019).

Taken all together, our study provides novel evidence on how parental separation impacts family life and parents' and children's daily activities. These findings have strong social policy implications. First, separation not only leads mothers to experiencing a motherhood wage penalty, but also a time penalty. Promoting gender equality in caring responsibilities after divorce (e.g., via shared child joint custody) could bring improvements in mother's career advancements, with separated fathers potentially working more on the care of their children. Second, the fact that boys' school-relevant activities (i.e., educational versus unstructured leisure) are disproportionally harmed by separation is relevant to inform policy makers and educators regarding gendered educational and behavioural outcomes among young people. We hope our study will inspire new research on the (gendered) nature of divorce in affecting parents' and children's daily lives and well-being over the life course. 


\section{REFERENCES}

Allison, Paul D. 1994. "Using Panel Data to Estimate the Effects of Events". Sociological Methods and Research, 23(2): 174-199.

Amato, Paul R. 1993. "Children's Adjustment to Divorce: Theories, Hypotheses, and Empirical Support". Journal of Marriage and Family, 55(1): 23-38.

Amato, Paul R. 2010. "Research on Divorce: Continuing Trends and New Developments". Journal of Marriage and Family, 72(3): 650-666.

Amato, Paul R. and Christopher Anthony. 2014. "Estimating the Effects of Parental Divorce and Death Using Fixed-Effects Models". Journal of Marriage and Family, 76(2): 370-386.

Astone, Nan M. and Sara Mclanahan. 1991. "Family Structure, Parental Practices and High School Completion". American Sociological Review, 56: 309-320.

Australian Bureau of Statistics 2013. "ANZSCO - Australian and New Zealand Standard Classification of Occupations". https://www.abs.gov.au/ausstats/abs@.nsf/mf/1220.0 Accessed 20 February 2020.

Baker, Michael and Kevin Milligan. 2016. "Boy-Girl Differences in Parental Time Investments: Evidence from Three Countries". Journal of Human Capital, 10(4): 1-44.

Bastaits, Kim, Koen Ponnet, Peer Van and Dimitri Mortelmans. 2015. "The Parenting Styles of Divorced Fathers and Their Predictors". Journal of Social and Personal Relationships, 32: 557579.

Beyens, Ine, Patti M. Valkenburg, and Jessica T. Piotrowski. 2018. "Screen Media Use and ADHDRelated Behaviors: Four Decades of Research". Proceedings of the National Academy of Sciences, 115(40): 9875-9881.

Bianchi, Suzanne M., John P. Robinson and Melissa A. Milke. 2006. The Changing Rhythms of American Family Life. Maryland: Russell Sage Foundation.

Bonke, Jens, and Gosta Esping-Andersen. 2011. "Family Investments in Children-Productivities, Preferences, and Parental Child Care". European Sociological Review, 27(1): 43-55.

Bono, Emilia Del, Marco Francesconi, Yvonne Kelly, and Amanda Sacker. 2016. Early maternal time investment and early child outcomes. The Economic Journal, 126(596): 96-F135.

Booth, Alan and Paul R. Amato. 1991. "Divorce and Psychological Stress". Journal of Health and Social Behavior, 32(4): 396-407.

Brady, David, Ryan M. Finnigan, and Sabine Hübgen. 2017. "Rethinking the risks of poverty: A framework for analyzing prevalences and penalties." American Journal of Sociology, 123(3): 740-786.

Carlson, Marcia J. 2006. "Family Structure, Father Involvement, and Adolescent Behavioral Outcomes". Journal of Marriage and Family, 68(1): 137-154.

Carlson, Marcia J., and Lawrence M. Berger. 2013. "What kids get from parents: Packages of parental involvement across complex family forms." Social Service Review 87(2), 213-249.

Chatzitheochari, Stella, and Sara Arber 2012. "Class, gender and time poverty: a time-use analysis of British workers' free time resources". The British Journal of Sociology, 63, 3, 451-471.

Cheadle, Jacob E., Paul R. Amato and Valarie King. 2010. "Patterns of Nonresident Father Contact". Demography, 47(1): 205-225.

Chetty, Raj, Nathaniel Hendren, Maggie R. Jones, and Sonya R. Porter. 2020. "Race and economic opportunity in the United States: An intergenerational perspective." The Quarterly Journal of Economics, 135(2): 711-783. 
Craig, Lyn. 2006. "Does Father Care Mean Fathers Share? A Comparison of How Mothers and Fathers in Intact Families Spend Time with Children”. Gender \& Society, 20(2): 259-281.

Craig, Lyn, Abigail Powell, and Ciara Smyth. 2006. "Towards intensive parenting? Changes in the composition and determinants of mothers' and fathers' time with children 1992-2006." The British Journal of Sociology, 65, 3 (2014): 555-579.

Craig, Lyn and Killian Mullan. 2012. "Lone and Partnered Mothers' Childcare Time Within Context in Four Countries". European Sociological Review, 28(4): 512-526.

Coleman, James S. 1988. "Social Capital in the Creation of Human Capital". American Journal of Sociology, 94(1): 95-120.

Corey, Joanne, Jenny Gallagher, Elisabeth Davis, and Michelle Marquardt. 2014. "The Times of Their Lives: Collecting Time Use Data from Children in The Longitudinal Study of Australian Children (LSAC)". LSAC Technical Paper, 13.

Coverman, Shelley. 1985. "Explaining husbands' participation in domestic labor." Sociological quarterly, 26(1): 81-97.

Del Boca, Daniela, Chiara Monfardini and Chetti Nicoletti. 2017. "Parental and Child Time Investments and The Cognitive Development of Adolescents". Journal of Labor Economics, 35(2): 565-608.

DiPrete, Thomas A. and Jennifer L. Jennings. 2012. "Social and Behavioral Skills and The Gender Gap in Early Educational Achievement". Social Science Research, 41(1): 1-15.

Epstein, Debbie. 1998. "Real Boys Don't Work: Underachievement, Masculinity and The Harassment of Sissies". In Debbie Epstein, Jannette Elwood, Valerie Hey and Janet Maw (Ed), Failing Boys? Issues in Gender and Achievement (pp. 96-108). Buckingham. United Kingdom: Open University Press.

Fiorini, Mario and Michael Keane. 2014. "How the Allocation of Children's Time Affects Cognitive and Noncognitive Development.” Journal of Labor Economics, 32(1): 787-834.

Fisher, Kimberly, Jonathan Gershuny, Evrim Altintas and Anne Gauthier. 2012. "Multinational Time Use Study: User's Guide and Documentation". University of Oxford, Oxford.

Fujiwara, T., Isumi, A., Ochi, M. and Kato, T., 2018. "Relationship between leaving children at home alone and their mental health: results from the A-CHILD Study in Japan." Frontiers in Psychiatry, 9: 192-201.

Furstenberg, Frank F., Christine W. Nord, James L. Peterson and Nicholas Zill. 1983. "The Life Course of Children of Divorce: Marital Disruption and Parental Contact". American Sociological Review, 48(5): 656-668.

Glenn, Evelyn N., Grace Chang and Linda R. Forcey. 2016. Mothering. Ideology, Experience, and Agency. New York: Routledge.

Goffman, Erving. 1976. "Gender display”. In Gender advertisements (pp. 1-9). Palgrave, London.

Gratz, Michael. 2017. "Does Separation Really Lead Fathers and Mothers to Be Less Involved in Their Children's Lives?” European Sociological Review, 33(4): 551-562.

Guiso, Luigi, Ferdinando M. Monte, Paola Sapienza and Luigi Zingales. 2008. "Culture, Gender and Math". Science, 5880(320): 1164-1165.

Harkonen, Juho 2017. "Divorce: Trends, Patterns, Causes, Consequences". In Judith Treas, Jacqueline Scott, and Martin Richards (Eds.), The Wiley-Blackwell Companion to The Sociology of Families (pp. 303-322). 
Harkonen, Juho, Fabrizio Bernardi and Diederik Boertien. 2017. "Family Dynamics and Child Outcomes: An Overview of Research and Open Questions". European Journal of Population, 33(2): 163-184.

Harris, Kathleen M., and Philip S. Morgan. 1991. "Fathers, Sons, and Daughters: Differential Paternal Involvement in Parenting". Journal of Marriage and The Family, 53(3): 531-544.

Haux, Tina and Lucinda Platt. 2020. "The Consequences of Separation for Mothers' Perception of Their Parenting Capacity". In Kreyenfeld, Michaela and Trappe, Heike (Eds.) Parental Life Courses after Separation and Divorce in Europe. Cham: Springer Nature Switzerland.

Hays, Sharon 1998. "The Cultural Contradictions of Motherhood”. New Heaven: Yale University Press.

Hetherington, E. Mavis, Margaret M. Stanley-Hagan. 1997. "The Effects of Divorce on Fathers and Their Children". In Lamb, Michael E. (Ed.). The Role of The Father in Child Development (3rd ed., pp. 191-211). New York, NY: Wiley.

Hofferth, Sandra, Pamela Davis-Kean and Jonathan Finklestein. 1997. "The Child Development Supplement to The Panel Study of Income Dynamics User Guide”. Ann Arbor: Survey Research Centre, University of Michigan.

Hsin, Amy. 2009. Parent's time with children: Does time matter for children's cognitive achievement?. Social Indicators Research, 93(1): 123-126.

Kalil, Ariel, Rebecca Ryan and Michael Corey. 2012. "Diverging Destinies: Maternal Education and The Educational Gradient in Time with Children". Demography, 49: 1361-1383.

Kalil, Ariel, Rebecca Ryan and Elise Chor. 2014. "Time Investments Across Family Structures". The ANNALS of The American Academy of Political and Social Sciences, 654(1): 150-168.

Kalmijn, Matthijs 2015. "How Childhood Circumstances Moderate the Long-Term Impact of Divorce on Father-Child Relationships". Journal of Marriage and Family, 77(4): 921-938.

Kalmijn, Matthijs, Suzanne G. de Leeuw, Maaike Hornstra, Katya Ivanova, Ruben van Gaalen and Kirsten van Houdt. 2019. "Family Complexity into Adulthood: The Central Role of Mothers in Shaping Intergenerational Ties". American Sociological Review, 84(5): 876-904.

Kan, Man Y. 2008. "Measuring Housework Participation: The Gap Between "Stylised" Questionnaire Estimates and Diary-Based Estimates". Social Indicators Research, 86(3): 381-400.

Kelly, Yvonne, Afshin Zilanawala, Cara Booker, and Amanda Sacker. 2019. "Social Media Use and Adolescent Mental Health: Findings from The UK Millennium Cohort Study". EClinicalMedicine, 6: 59-68.

Kiernan, Kathleen E. and Maria Carmen Huerta. 2008. "Economic Deprivation, Maternal Depression, Parenting and Children's Cognitive and Emotional Development in Early Childhood." British Journal of Sociology, 59(4), 783-806.

Kim, Hyun S. 2011. "Consequences of Parental Divorce for Child Development". American Sociological Review, 76(3): 487-511.

Koppen, Katja, Michaela Kreyenfeld and Heike Trappe. 2018. "Loose Ties? Determinants of FatherChild Contact after Separation in Germany". Journal of Marriage and Family, 80(5): 11631175.

Kreyenfeld, Michaela and Heike Trappe (Eds.) 2020. "Parental Life Courses after Separation and Divorce in Europe”. Cham: Springer Nature Switzerland.

Lareau, Annette 2011. "Unequal Childhoods: Class, Race and Family Life”, 2nd Edition. Berkeley: University of California Press. 
Leopold, Thomas 2018. "Gender Differences in The Consequences of Divorce: A Study of Multiple Outcomes”. Demography, 55(1): 769-797.

Leopold, Thomas, and Matthijs Kalmijn. 2016. "Is Divorce More Painful When Couples Have Children? Evidence from Long-Term Panel Data on Multiple Domains of WellBeing”. Demography, 53(6), 1717-1742.

Legewie, Joscha, and Thomas A. DiPrete. 2012. "School Context and The Gender Gap in Educational Achievement". American Sociological Review, 77(3): 463-485.

Lersch, Philipp M. and Janeen Baxter. 2020. "Parental Separation During Childhood and Adult Children's Wealth". Social Forces.

Lundberg, Shelly. 2005. "Sons, Daughters, and Parental Behaviour". Oxford Review of Economic Policy, 21(3): 340-356.

McLanahan, Sara, Laura Tach and Daniel Schneider. 2013. "The Causal Effects of Father Absence". Annual Review of Sociology, 39: 399-427.

Meier, Ann, Kelly Musick, Sarah Flood and Rachel Dunifon. 2016. "Mothering Experiences: How Single Parenthood and Employment Structure the Emotional Valence of Parenting". Demography, 53(3): 649-674.

Mencarini, Letizia, Silvia Pasqua and Agnese Romiti. 2019. "Single-Mother Families and The Gender Gap in Children's Time Investment and Non-Cognitive Skills". Review of Economics of the Household, 17(1): 149-176.

Morris, Edward W. 2008. "“Rednecks,' 'Rutters,' and 'Rithmetic'”. Gender and Society, 22(1): 728751.

Mortelmans Dimitri. 2020. Economic Consequences of Divorce: A Review. In: Kreyenfeld M., Trappe H. (eds) Parental Life Courses after Separation and Divorce in Europe. Life Course Research and Social Policies, vol 12 (pp. 23-41). Springer, Cham.

Mullan, Killian 2014. "Longitudinal Analysis of LSAC Time Diary Data: Considerations For Data Users”. Australian Institute of Family Studies, Australian Government Department of Social Services. https://growingupinaustralia.gov.au/sites/default/files/tp11.pdf. Accessed 2 February 2020.

OECD. 2018. "Family Database". Paris: OECD. https://stats.oecd.org/index.aspx?queryid=68249.

Pardo, Ignacio, Teresa Martín-García, Teresa Castro-Martín and Wanda Cabella. 2019. "Fatherhood After Union Breakup in Uruguay: Transitory or Life-Long Commitment?”. Journal of Family Issues, 41(6): 784-807.

Pasteels, Inge and Kim Bastaits. 2020. "Loneliness in Children Adapting to Dual Family Life." In Kreyenfeld, Michaela and Trappe, Heike (Eds.) Parental Life Courses after Separation and Divorce in Europe. Cham: Springer Nature Switzerland.

Pepin, Joanna R., Liana C. Sayer and Lynne M. Casper. 2018. “Marital Status and Mothers' Time Use: Childcare, Housework, Leisure, and Sleep". Demography, 55(1): 107-133.

Rane, Thomas R. and Brent A. McBride. 2000. "Identity Theory as a Guide to Understanding Fathers' Involvement with Their Children." Journal of Family Issues 21:347-66.

Raley, Sara and Suzanne Bianchi. 2006. "Sons, Daughters, and Family Processes: Does Gender of Children Matter?". Annual Review of Sociology, 32(1): 401-421.

Ressler, Robert W., Chelsea Smith, Shannon Cavanagh, and Robert Crosnoe. 2016. “Mothers' Union Statuses and Their Involvement in Young Children's Schooling”. Journal of Marriage and Family, 79(1): 94-109. 
Roekel, Eeske van, Ron H. J. Scholte, Rutger C. M. E. Engels, Luc Goossens, and Maaike Verhagen. 2015. "Loneliness in the Daily Lives of Adolescents: An Experience Sampling Study Examining the Effects of Social Contexts." Journal of Early Adolescence 35(7): 905-30.

Rutter, Michael. 1987. "Psychosocial Resilience and Protective Mechanisms". American Journal of Orthopsychiatry, 57(3): 316-331.

Smyth, Bruce M. and Richard Chisholm. 2017. "Shared-Time Parenting after Separation in Australia: Precursors, Prevalence, and Postreform Patterns". Family Court Review, 55(4): 586-603.

Stryker, Sheldon. 1968. "Identity Salience and Role Performance: The Relevance of Symbolic Interaction Theory for Family Research." Journal of Marriage and the Family, 30:558-64.

Todd, Petra, and Kenneth Wolpin. 2007. "On the Specification and Estimation of The Production Function for Cognitive Achievement". The Economic Journal, 113: F3-F33.

West, Candance, and Don H. Zimmerman. 1987. "Doing Gender". Gender and society, 1(2): 125-151.

Westphal, Sarah K., Anne Rigt Poortman and Tanja Van Der Lippe. 2014. "Non-Resident FatherChild Contact Across Divorce Cohorts: The Role of Father Involvement During Marriage". European Sociological Review, 30(4): 444-456.

Wight, Vanessa R., Joseph Price, Suzanne M. Bianchi and Bijou R. Hunt. 2009. "The Time-Use of Teenagers". Social Science Research, 38(4): 792-809.

Wooldridge, Jeffrey M. 2010. “Econometric Analysis of Cross Section and Panel Data”. Cambridge: MIT press. 


\section{TABLES AND FIGURES}

Table 1. Summary Statistics. Means and Standard Deviations

\begin{tabular}{|c|c|c|c|c|c|}
\hline & \multicolumn{2}{|c|}{ Not Separated } & \multicolumn{2}{|c|}{ Separated Sample } & \multirow{2}{*}{$\frac{\text { Diff. }}{p}$} \\
\hline & Mean & $S D$ & Mean & $S D$ & \\
\hline \multicolumn{6}{|l|}{ Dependent Variables (in daily minutes) } \\
\hline Mother-child solo time & 164.32 & 194.74 & 212.98 & 240.38 & $* * *$ \\
\hline Father-child solo time & 39.97 & 85.89 & 41.84 & 109.82 & \\
\hline Two-parents' time & 157.51 & 231.95 & 124.94 & 231.97 & $* * *$ \\
\hline Time alone & 236.42 & 253.24 & 222.31 & 252.93 & $*$ \\
\hline Educational activities & 122.48 & 103.34 & 115.57 & 108.31 & $*$ \\
\hline Unstructured leisure & 139.07 & 119.54 & 150.06 & 121.70 & $* * *$ \\
\hline \multicolumn{6}{|l|}{ Independent and Control Variables } \\
\hline Father has a college degree & 0.35 & & 0.24 & & $* * *$ \\
\hline Mother has college degree & 0.39 & & 0.27 & & $* * *$ \\
\hline Father is not employed & 0.04 & & 0.06 & & \\
\hline Father has a working-class occupation & 0.40 & & 0.55 & & $* * *$ \\
\hline Father has an intermediate occupation & 0.17 & & 0.14 & & $* *$ \\
\hline Father has a managerial/professional job & 0.39 & & 0.25 & & $* * *$ \\
\hline Mother is not employed & 0.24 & & 0.26 & & $*$ \\
\hline Mother has a working-class occupation & 0.31 & & 0.31 & & \\
\hline Mother has an intermediate occupation & 0.18 & & 0.19 & & \\
\hline Mother has a managerial/professional job & 0.27 & 0.44 & 0.22 & 0.42 & $* * *$ \\
\hline Child's age in months & 114.99 & 41.36 & 113.56 & 41.29 & \\
\hline Child is a girl & 0.49 & & 0.52 & & $*$ \\
\hline Child speaks English at home & 0.90 & & 0.94 & & $* * *$ \\
\hline At least one other child in the household & 0.45 & & 0.44 & & \\
\hline \multicolumn{6}{|l|}{ State of Residence: } \\
\hline New South Wales & 0.31 & & 0.30 & & $*$ \\
\hline Victoria & 0.25 & & 0.23 & & \\
\hline Queensland & 0.20 & & 0.23 & & $* *$ \\
\hline South Australia & 0.07 & & 0.07 & & \\
\hline Western Australia & 0.11 & & 0.08 & & $* *$ \\
\hline Tasmania & 0.03 & & 0.03 & & \\
\hline Northern Territory & 0.01 & & 0.02 & & \\
\hline Australian Capital Territory & 0.03 & & 0.03 & & \\
\hline Re-partnering & 0.00 & & 0.09 & & $* * *$ \\
\hline Number of Observations & \multicolumn{2}{|c|}{12,808} & \multicolumn{2}{|c|}{2,054} & \\
\hline Number of Children & \multicolumn{2}{|c|}{3,214} & \multicolumn{2}{|c|}{505} & \\
\hline
\end{tabular}

Source: Longitudinal Study of Australian Children. K Cohort, Waves 1 to 6 (2004-2014).

Note: Observations are pooled across waves. Difference column refers to differences between divorce and control samples, using t-test. Levels of significance: ${ }^{*} p<.05,{ }^{*} p<.01, * * * p<.001$. 


\section{Figure 1. Regression Models of Children's Time with Parents and Alone - Average Effect}
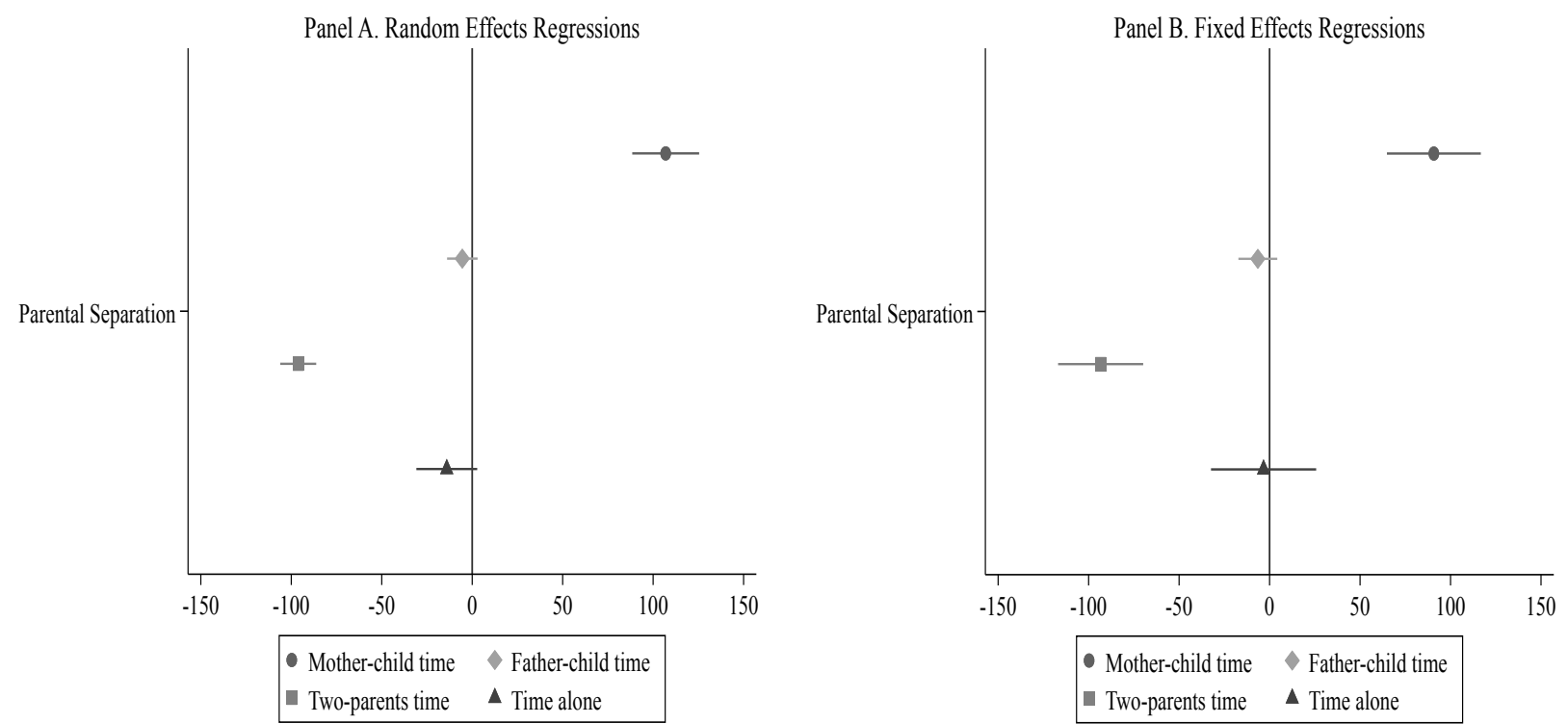

Source: Longitudinal Study of Australian Children. K Cohort, Waves 1 to 6 (2004-2014).

Note: Both the Random Effects (Panel A) and Fixed Effects (Panel B) regressions include four separate models, controlling for child age, maternal education, paternal education, mother's class, father's class, language spoken at home, number of siblings, region of residence, and residential parent re-partnering. Child's sex is only included in the Random Effects models. Confidence Intervals are included at the $95 \%$ level (Number of diary observations $=14,862$ ).

\section{Figure 2. Regression Models of Children's Time with Parents and Alone - Long-Term Effect}

Panel A. Random Effects Regressions

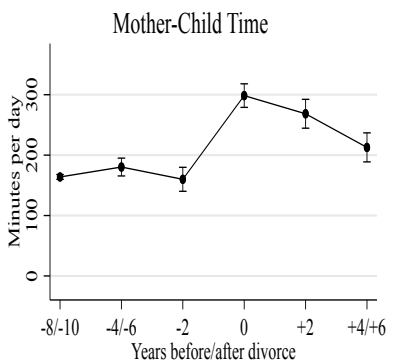

Two-Parents Time

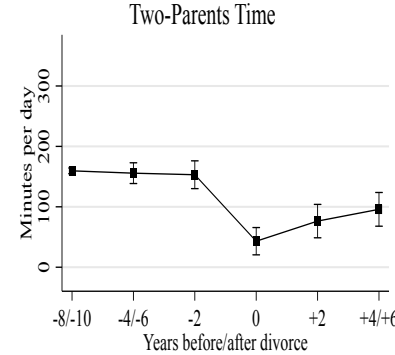

Father-Child Time

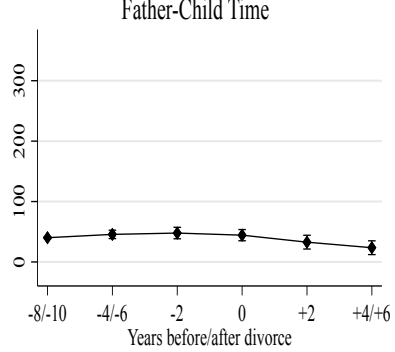

Time Alone

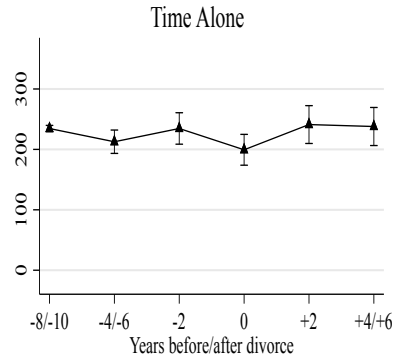

Panel B. Fixed Effects Regressions
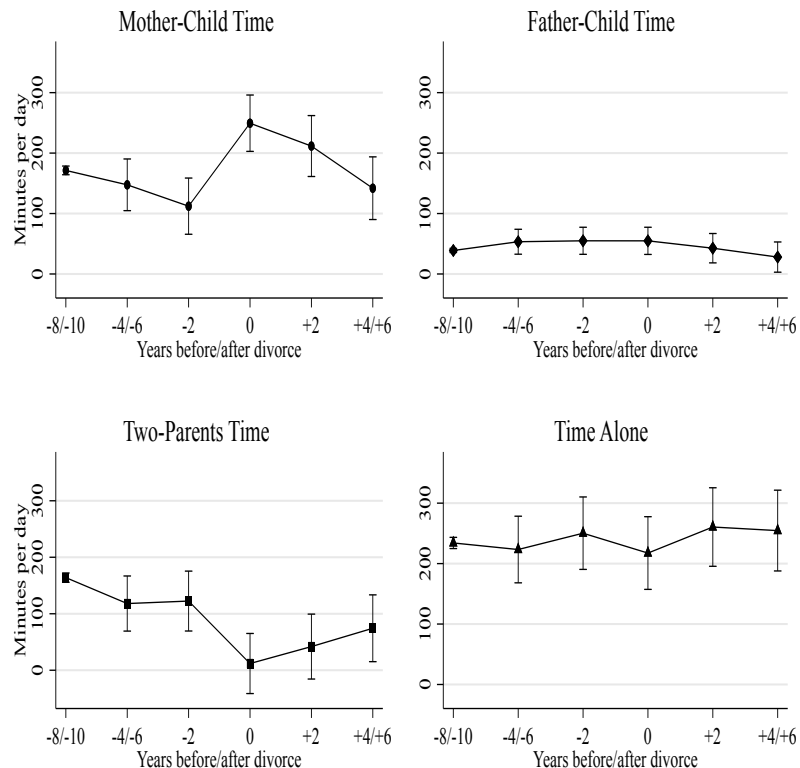

Source: Longitudinal Study of Australian Children. K Cohort, Waves 1 to 6 (2004-2014)

Note: Both the Random Effects (Panel A) and Fixed Effects (Panel B) regressions include four separate models, controlling for child age, maternal education, paternal education, mother's class, father's class, language spoken at home, number of siblings, region of residence, and residential parent re-partnering. Child's sex is only included in the Random Effects models. Confidence Intervals are included at the $95 \%$ level (Number of diary observations $=14,862$ ). 
Figure 3. Regression Models of Children's Time in Educational and Unstructured Activities Average Effect.
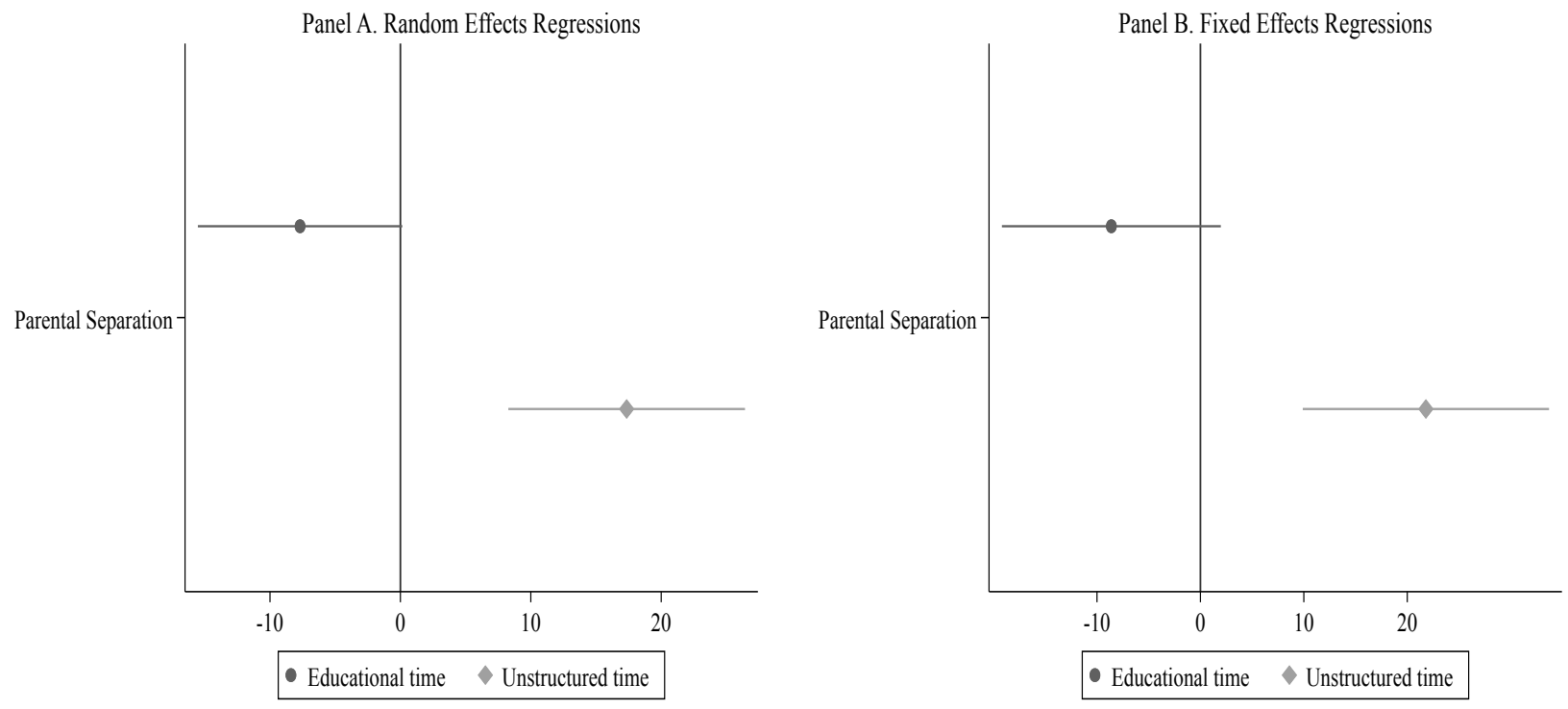

Source: Longitudinal Study of Australian Children. K Cohort, Waves 1 to 6 (2004-2014).

Note: Both the Random Effects (Panel A) and Fixed Effects (Panel B) regressions include two separate models, controlling for child age, maternal education, paternal education, mother's class, father's class, language spoken at home, number of siblings, region of residence, and residential parent re-partnering. Child's sex is included in the Random Effects models only. Confidence Intervals are included at the $95 \%$ level (Number of diary observations $=14,862$ ).

\section{Figure 4. Regression Models of Children Time in Educational and Unstructured Activities - Long-Term Effect}

Panel A. Random Effects Regressions

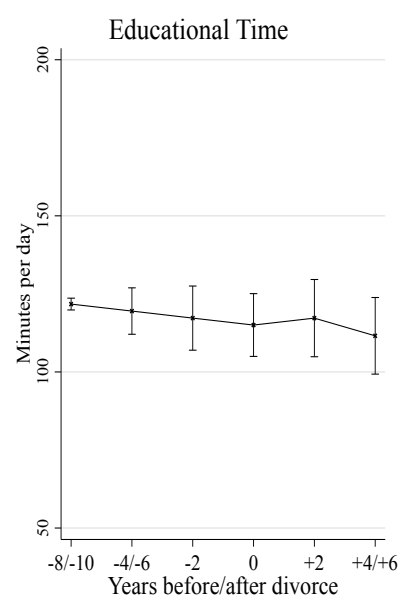

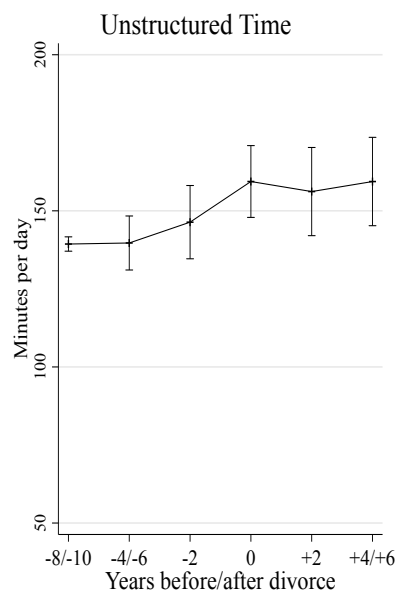

Panel B. Fixed Effects Regressions

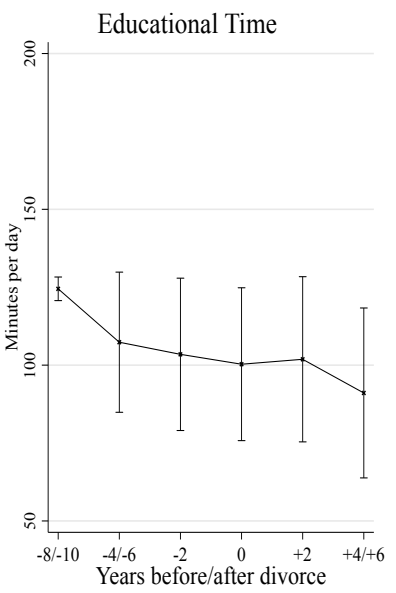

Source: Longitudinal Study of Australian Children. K Cohort, Waves 1 to 6 (2004-2014)

Note: Both the Random Effects (Panel A) and Fixed Effects (Panel B) regressions include two separate models, controlling for child age, maternal education, paternal education, mother's class, father's class, language spoken at home, number of siblings, region of residence, and residential parent re-partnering. Child age is included in the Random Effects models only. Confidence Intervals are included at the $95 \%$ level (Number of diary observations $=14,862$ ). 


\section{Figure 5. Random-Effects Regression Models of Child Time Use by Child Gender}

Panel A. Average Effects

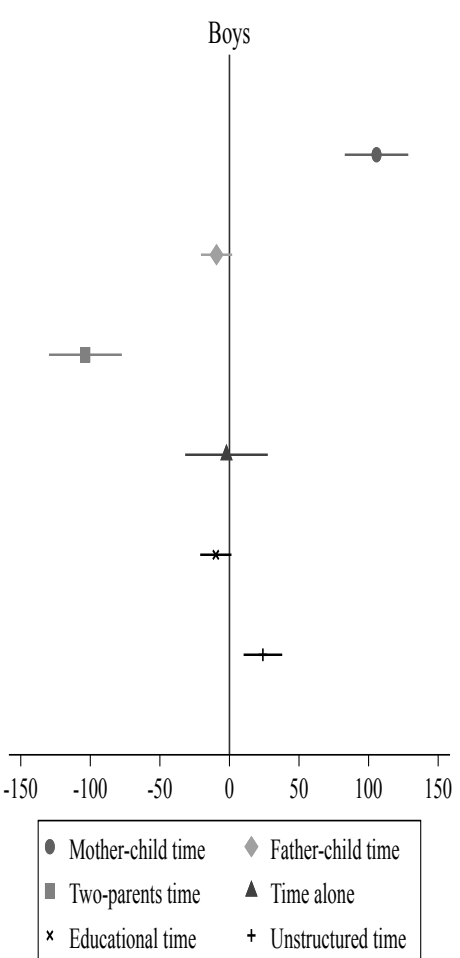

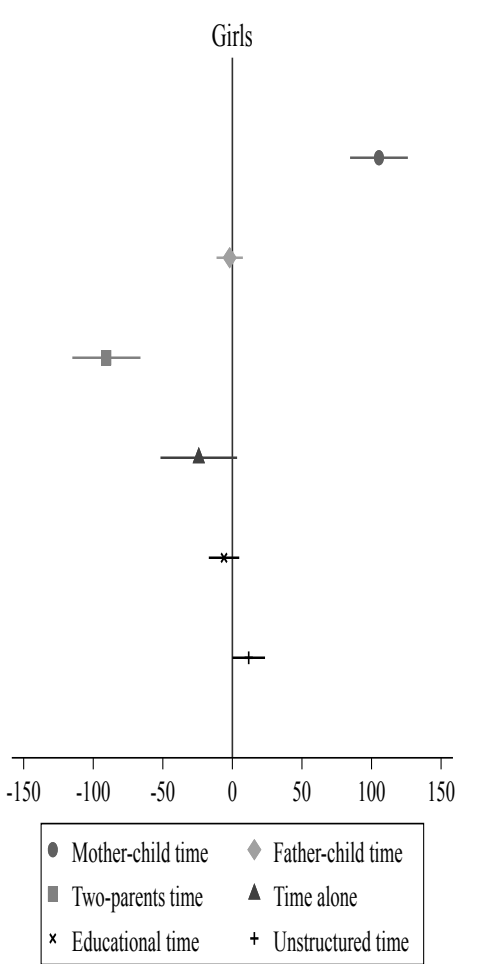
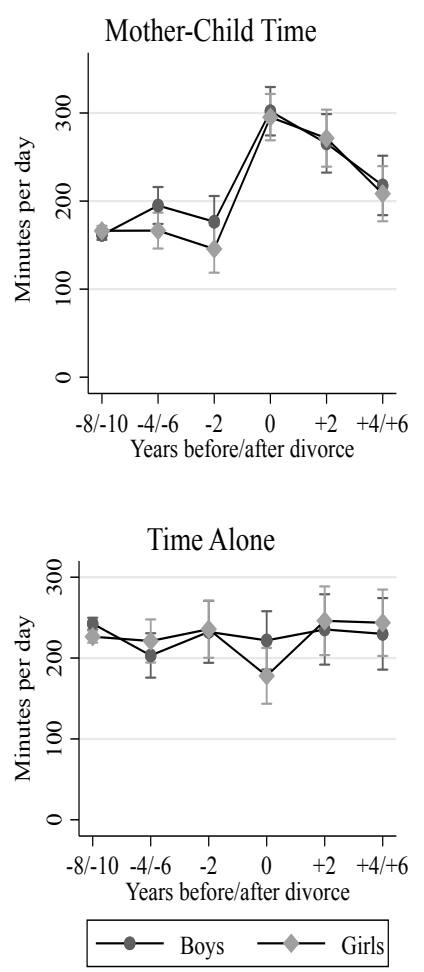

Panel B. Long-Term Effects
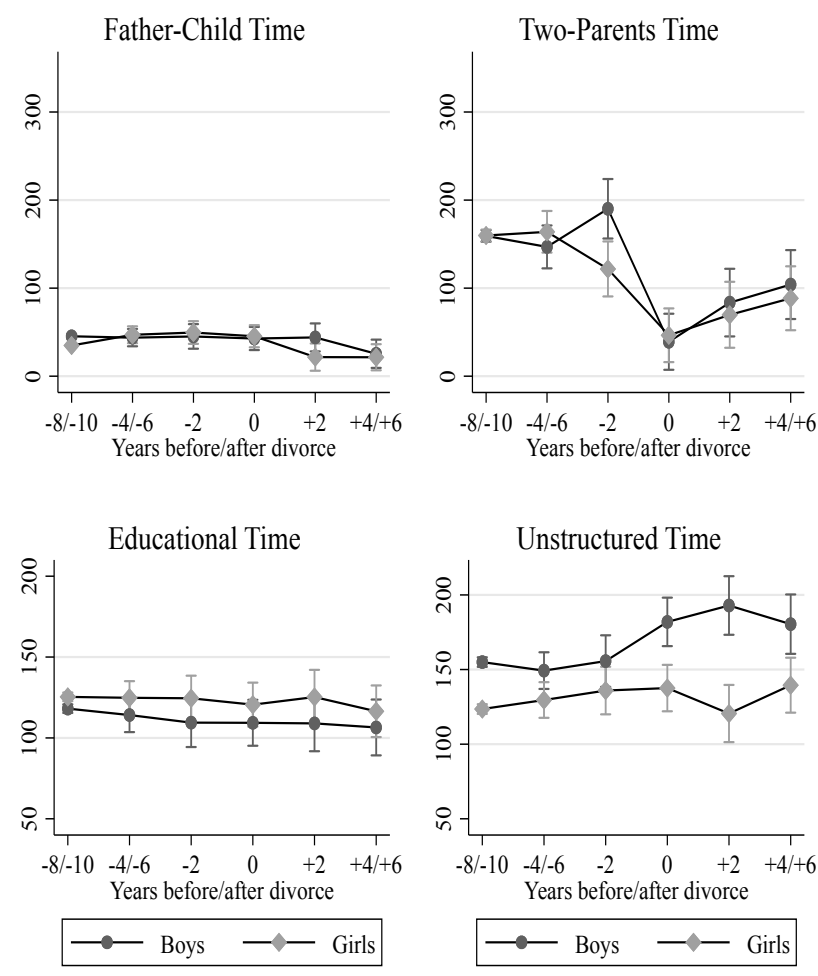

Source: Longitudinal Study of Australian Children. K Cohort, Waves 1 to 6 (2004-2014).

Note: Panel A shows regression estimated separately in two subsamples of girls and boys (i.e., twelve regressions, six per girls and six per boys). Panel B shows six regressions where each of them includes an interaction term between child's sex and separation in a categorical form that indexes years before and after. All models control for child age, maternal education, paternal education, mother's class, father's class, language spoken at home, number of siblings, region of residence, and residential parent re-partnering. Confidence Intervals are included at the $95 \%$ level (Number of observations $=14,862$ ) 
Table 2: Value-Added Regression Models of Child Time-Use by Child Age

\begin{tabular}{|c|c|c|c|c|c|c|c|c|c|c|c|c|}
\hline \multirow[b]{2}{*}{ Panel A: Age 4-6 } & \multicolumn{2}{|c|}{$\begin{array}{c}\text { Mother-Child } \\
\text { Solo Time } \\
\end{array}$} & \multicolumn{2}{|c|}{$\begin{array}{l}\text { Father-Child } \\
\text { Solo Time } \\
\end{array}$} & \multicolumn{2}{|c|}{$\begin{array}{c}\text { Two-Parents' } \\
\text { Time } \\
\end{array}$} & \multicolumn{2}{|c|}{$\begin{array}{c}\text { Time } \\
\text { Alone }\end{array}$} & \multicolumn{2}{|c|}{ Educational Activities } & \multicolumn{2}{|c|}{$\begin{array}{c}\text { Unstructured } \\
\text { Activities }\end{array}$} \\
\hline & $\beta$ & $S E$ & $\beta$ & $S E$ & $\beta$ & $S E$ & $\beta$ & $S E$ & $\beta$ & $S E$ & $\beta$ & $S E$ \\
\hline Separation & $225.65^{* * *}$ & 28.07 & $67.25^{* * *}$ & 13.15 & $-187.91^{* * *}$ & 34.74 & $-144.81^{* * *}$ & 39.24 & -10.29 & 11.46 & 4.04 & 8.27 \\
\hline Intercept & $189.60^{* * *}$ & 21.65 & $40.54^{* * *}$ & 10.14 & $228.27^{* * *}$ & 26.80 & $160.38^{* * *}$ & 30.27 & $114.57^{* * *}$ & 8.84 & $71.01^{* * *}$ & 6.38 \\
\hline Controls & \multicolumn{2}{|c|}{ YES } & \multicolumn{2}{|c|}{ YES } & \multicolumn{2}{|c|}{ YES } & \multicolumn{2}{|c|}{ YES } & \multicolumn{2}{|c|}{ YES } & \multicolumn{2}{|c|}{ YES } \\
\hline$R^{2}$ & \multicolumn{2}{|c|}{0.07} & \multicolumn{2}{|c|}{0.03} & \multicolumn{2}{|c|}{0.09} & \multicolumn{2}{|c|}{0.18} & \multicolumn{2}{|c|}{0.05} & \multicolumn{2}{|c|}{0.07} \\
\hline Number of observations & \multicolumn{2}{|c|}{2,104} & \multicolumn{2}{|c|}{2,104} & \multicolumn{2}{|c|}{2,104} & \multicolumn{2}{|c|}{2,104} & \multicolumn{2}{|c|}{2,104} & \multicolumn{2}{|c|}{2,104} \\
\hline Panel B: Age 6-8 & $\beta$ & $S E$ & $\beta$ & $S E$ & $\beta$ & $S E$ & $\beta$ & $S E$ & $\beta$ & $S E$ & $\beta$ & $S E$ \\
\hline Separation & $252.81^{* * *}$ & 18.31 & $21.92^{*}$ & 8.40 & $-209.01^{* * *}$ & 23.34 & $-99.09^{* * *}$ & 24.79 & -8.99 & 7.45 & 4.67 & 5.75 \\
\hline Intercept & $188.28^{* * *}$ & 14.23 & $42.73^{* * *}$ & 6.33 & $181.02^{* * *}$ & 17.84 & $117.84^{* * *}$ & 18.23 & $111.14^{* * *}$ & 5.9 & $64.23^{* * *}$ & 4.75 \\
\hline Controls & \multicolumn{2}{|c|}{ YES } & \multicolumn{2}{|c|}{ YES } & $\mathrm{YE}$ & & $\mathrm{YE}$ & & $\mathrm{Y}$ & & $\mathrm{YH}$ & \\
\hline$R^{2}$ & 0.0 & & & & 0.1 & & 0.1 & & 0 . & & 0. & \\
\hline Number of observations & 4,10 & & & & 4,1 & & 4,1 & & 4,1 & & 4,1 & \\
\hline Panel C: Age 8-10 & $\beta$ & $S E$ & $\beta$ & $S E$ & $\beta$ & $S E$ & $\beta$ & $S E$ & $\beta$ & $S E$ & $\beta$ & $S E$ \\
\hline Separation & $146.49^{* * *}$ & 11.98 & -4.27 & 5.09 & $-128.11^{* * *}$ & 14.05 & $-40.15^{* *}$ & 15.65 & $-10.66^{*}$ & 5.77 & 10.39 & 7.05 \\
\hline Intercept & $214.18^{* * *}$ & 13.27 & $45.10^{* * *}$ & 6.66 & $253.75^{* * *}$ & 16.34 & $214.65^{* * *}$ & 17.33 & $125.30^{* * *}$ & 6.39 & $93.75^{* * *}$ & 7.81 \\
\hline Controls & $\mathrm{YE}$ & & & & $\mathrm{YE}$ & & $\mathrm{YE}$ & & $\mathrm{Y}$ & & $\mathrm{YH}$ & \\
\hline$R^{2}$ & 0.1 & & & & 0.1 & & 0.1 & & & & 0 . & \\
\hline Number of observations & 4,22 & & & & 4,2 & & 4,2 & & 4,2 & & 4,2 & \\
\hline Panel D: Age 10-12 & $\beta$ & $S E$ & $\beta$ & $S E$ & $\beta$ & $S E$ & $\beta$ & $S E$ & $\beta$ & $S E$ & $\beta$ & $S E$ \\
\hline Separation & $66.01^{* * *}$ & 6.29 & -3.66 & 4.24 & $-72.44^{* * *}$ & 5.42 & -3.92 & 7.92 & -7.27 & 5.26 & $14.97^{*}$ & 6.66 \\
\hline Intercept & $90.76^{* * *}$ & 7.38 & 37.66 & 4.86 & $75.07^{* * *}$ & 6.43 & $176.76^{* * *}$ & 9.36 & $92.05^{* * *}$ & 6.46 & $158.16^{* * *}$ & 7.77 \\
\hline Controls & $\mathrm{YE}$ & & & & $\mathrm{YE}$ & & $\mathrm{YE}$ & & $\mathrm{Y}$ & & $\mathrm{YH}$ & \\
\hline$R^{2}$ & 0.0 & & & & 0.0 & & 0.0 & & 0. & & $0 .($ & \\
\hline Number of observations & 4,70 & & & & 4,7 & & 4,7 & & 4,7 & & 4,7 & \\
\hline Panel E: Age 12-14 & $\beta$ & $S E$ & $\beta$ & $S E$ & $\beta$ & $S E$ & $\beta$ & $S E$ & $\beta$ & $S E$ & $\beta$ & $S E$ \\
\hline Separation & $64.24^{* * *}$ & 5.97 & $-10.54^{* *}$ & 4.10 & $-73.93^{* * *}$ & 5.30 & $11.99^{+}$ & 8.85 & $-12.04^{*}$ & 5.01 & $16.80^{*}$ & 7.20 \\
\hline Intercept & $85.04^{* * *}$ & 7.96 & $38.11^{* * *}$ & 5.47 & $77.01^{* * *}$ & 7.06 & $197.54^{* * *}$ & 11.79 & $119.71^{* * *}$ & 6.81 & $183.64^{* * *}$ & 9.60 \\
\hline Controls & $\mathrm{YE}$ & & & & $\mathrm{YE}$ & & $\mathrm{YE}$ & & $\mathrm{Y}$ & & $\mathrm{Yl}$ & \\
\hline$R^{2}$ & 0.1 & & & & 0.0 & & 0.1 & & 0 . & & 0. & \\
\hline Number of observations & 4,81 & & & & 4,8 & & 4,8 & & 4,8 & & 4,8 & \\
\hline
\end{tabular}

Source: Longitudinal Study of Australian Children. K Cohort. Panel A includes waves 1-2; Panel B, waves 2-3; Panel C, waves 3-4; Panel D, waves 4-5 and Panel E, waves 5-6.

Note: Models control for the lagged dependent variable, child sex, child age, maternal education, paternal education, mother's class, father's class, language spoken at home, number of siblings, region of residence, and residential parent re-partnering. ${ }^{+} p<.10 * p<.05,{ }^{* *} p<.01,{ }^{* * *} p<.001$. 


\section{APPENDIX}

Table A1. Correspondence Between Activities and Time-Use Categories

\begin{tabular}{lll}
\hline Category & Activities Details & Location \\
\hline Mother-Child Solo Time & Any activity with the mother and without the father & Any place \\
Father-Child Solo Time & Any activity with the father and without the mother & Any place \\
Two-Parents' Time & Any activity in presence of both the mother and the father & Any place \\
Time Alone & Any activity alone, without the presence of others & Any place \\
Educational Activities & $\begin{array}{l}\text { Reading, study, homework (electronic or not), going to theatre, Outside School } \\
\text { opera, concerts, cinema, library time, doing music, dance, } \\
\text { theatre, artistic activities, structured sports, language lessons. }\end{array}$ \\
Unstructured Leisure & $\begin{array}{l}\text { Unstructured playing, watching TV, playing video games, Outside School } \\
\text { video watching, using mobile phones, illegal activities, } \\
\text { browsing on the internet (non-schooling related), social media } \\
\text { activities. }\end{array}$ \\
\hline
\end{tabular}

Source: Longitudinal Study of Australian Children. K Cohort, Waves 1 to 6 (2004-2014). 
Table A2. Random-Effect Models. Children's Daily Minutes. Parental Separation Average and Long-Term Effects

\begin{tabular}{|c|c|c|c|c|c|c|c|c|c|c|c|c|}
\hline & \multicolumn{2}{|c|}{$\begin{array}{l}\text { Mother-Child } \\
\text { Solo Time }\end{array}$} & \multicolumn{2}{|c|}{$\begin{array}{l}\text { Father-Child } \\
\text { Solo Time }\end{array}$} & \multicolumn{2}{|c|}{$\begin{array}{c}\text { Two-Parents' } \\
\text { Time }\end{array}$} & \multicolumn{2}{|c|}{$\begin{array}{l}\text { Time } \\
\text { Alone }\end{array}$} & \multicolumn{2}{|c|}{$\begin{array}{c}\text { Educational } \\
\text { Activities }\end{array}$} & \multicolumn{2}{|c|}{$\begin{array}{c}\text { Unstructured } \\
\text { Activities }\end{array}$} \\
\hline & $\beta$ & $S E$ & $\beta$ & $S E$ & $\beta$ & $S E$ & $\beta$ & $S E$ & $\beta$ & $S E$ & $\beta$ & $S E$ \\
\hline Separation Average Effects & $106.94^{* * *}$ & 7.87 & -5.47 & 3.73 & $-96.16^{* * *}$ & 9.13 & -14.05 & 10.32 & $-7.69^{+}$ & 4.00 & $17.35^{* * *}$ & 4.63 \\
\hline Girl & 5.23 & 3.76 & $-9.37^{* * *}$ & 1.71 & 1.76 & 4.43 & $-12.98^{* *}$ & 4.93 & $8.78^{* * *}$ & 1.79 & $-31.45^{* * *}$ & 2.17 \\
\hline 6 Years Old & $-90.16^{* * *}$ & 4.78 & $-11.32^{* * *}$ & 2.32 & $-35.25^{* * *}$ & 5.50 & $21.89^{* * *}$ & 6.27 & $-55.00^{* * *}$ & 2.54 & $-102.98^{* * *}$ & 2.85 \\
\hline 8 Years Old & $-89.37^{* * *}$ & 4.98 & $-12.07^{* * *}$ & 2.41 & 6.40 & 5.72 & $24.57^{* * *}$ & 6.52 & $-51.90^{* * *}$ & 2.64 & $-85.09^{* * *}$ & 2.96 \\
\hline 10 Years Old & $-192.32^{* * *}$ & 4.89 & $-22.76^{* * *}$ & 2.37 & $-180.22^{* * *}$ & 5.62 & $-109.47^{* * *}$ & 6.40 & $-110.61^{* * *}$ & 2.58 & $-26.89^{* * *}$ & 2.91 \\
\hline 12 Years Old & $-207.64^{* * *}$ & 7.15 & $-23.89^{* * *}$ & 3.44 & $-166.81^{* * *}$ & 8.25 & $-27.84^{* *}$ & 9.37 & $-57.14^{* * *}$ & 3.73 & $-15.51^{* * *}$ & 4.24 \\
\hline 14 Years Old & $-216.64^{* * *}$ & 7.36 & $-28.59^{* * *}$ & 3.54 & $-167.83^{* * *}$ & 8.50 & $45.64^{* * *}$ & 9.65 & $-90.18^{* * *}$ & 3.84 & $15.79^{* * *}$ & 4.36 \\
\hline Mother's College & 0.37 & 4.31 & $3.42^{+}$ & 1.99 & $-8.35^{+}$ & 5.06 & $12.23^{*}$ & 5.65 & $18.17^{* * *}$ & 2.08 & $-12.67^{* * *}$ & 2.50 \\
\hline Father's College & 1.87 & 4.42 & 0.49 & 2.03 & $-9.06^{+}$ & 5.19 & 1.22 & 5.79 & $13.97^{* * *}$ & 2.13 & $-10.22^{* * *}$ & 2.56 \\
\hline Mother: Manager or Professional Occupation & $-12.64^{*}$ & 6.08 & $8.11^{* *}$ & 2.91 & -10.30 & 7.02 & $31.38^{* * *}$ & 7.97 & $12.56^{* * *}$ & 3.14 & $-6.24^{+}$ & 3.59 \\
\hline Mother: Intermediate Class & -3.70 & 6.23 & -0.31 & 2.98 & 4.86 & 7.20 & $33.62^{* * *}$ & 8.17 & $8.26^{*}$ & 3.22 & $-7.37^{*}$ & 3.68 \\
\hline Mother: Not in Employment & $33.78^{* * *}$ & 5.42 & $-13.37^{* * *}$ & 2.58 & $-12.32^{*}$ & 6.28 & $29.66^{* * *}$ & 7.10 & $13.31^{* * *}$ & 2.77 & 3.36 & 3.19 \\
\hline Father: Manager or Professional Occupation & 2.38 & 5.34 & $-5.46^{*}$ & 2.55 & 6.74 & 6.19 & $33.43^{* * *}$ & 7.00 & $6.58^{*}$ & 2.74 & -0.95 & 3.15 \\
\hline Father: Intermediate Class & 2.14 & 5.86 & $-7.02^{*}$ & 2.79 & $11.55^{+}$ & 6.79 & $14.76^{+}$ & 7.68 & 3.66 & 3.00 & 1.51 & 3.45 \\
\hline Father: Not in Employment & $-66.50^{* * *}$ & 8.09 & $21.45^{* * *}$ & 3.85 & $43.91^{* * *}$ & 9.37 & 9.40 & 10.60 & 3.64 & 4.13 & $20.08^{* * *}$ & 4.77 \\
\hline Resident parent re-partners & $-99.92^{* * *}$ & 15.75 & $19.11^{*}$ & 7.52 & $82.62^{* * *}$ & 18.24 & $41.46^{*}$ & 20.65 & $18.36^{*}$ & 8.10 & -12.43 & 9.30 \\
\hline Intercept & $288.71^{* * *}$ & 9.54 & $70.50^{* * *}$ & 4.47 & $254.77^{* * * *}$ & 11.13 & $183.69^{* * *}$ & 12.51 & $163.11^{* * *}$ & 4.76 & $197.45^{* * *}$ & 5.58 \\
\hline Within $R^{2}$ & \multicolumn{2}{|c|}{0.18} & \multicolumn{2}{|c|}{0.03} & \multicolumn{2}{|c|}{0.15} & \multicolumn{2}{|c|}{0.07} & \multicolumn{2}{|c|}{0.16} & \multicolumn{2}{|c|}{0.17} \\
\hline Number of observations & \multicolumn{2}{|c|}{14862} & \multicolumn{2}{|c|}{14862} & \multicolumn{2}{|c|}{14862} & \multicolumn{2}{|c|}{14862} & \multicolumn{2}{|c|}{14862} & \multicolumn{2}{|c|}{14862} \\
\hline \multicolumn{13}{|l|}{$-10 /-8$ Years before Separation (ref) } \\
\hline$-6 /-4$ Years before Separation & $16.38^{*}$ & 7.77 & 5.49 & 3.66 & -3.84 & 9.05 & $-21.89^{*}$ & 10.19 & -2.23 & 3.91 & 0.33 & 4.56 \\
\hline - 2 Years before Separation & -3.93 & 10.32 & 7.71 & 4.93 & -6.45 & 11.96 & 0.10 & 13.54 & -4.49 & 5.33 & 7.00 & 6.10 \\
\hline 0 Years since Separation & $134.65^{* * *}$ & 10.20 & 4.19 & 4.86 & $-116.47^{* * *}$ & 11.82 & $-35.20^{* *}$ & 13.37 & -6.71 & 5.25 & $20.02^{* * *}$ & 6.02 \\
\hline + 2 Years after Separation & $104.55^{* * *}$ & 12.42 & -7.35 & 5.94 & $-83.18^{* * *}$ & 14.38 & 6.56 & 16.29 & -4.50 & 6.42 & $16.80^{*}$ & 7.34 \\
\hline$+4 /+6$ Years after Separation & $48.90^{* * *}$ & 12.51 & $-16.54^{* *}$ & 5.93 & $-63.73^{* * *}$ & 14.52 & 3.36 & 16.40 & -10.16 & 6.38 & $20.01^{* *}$ & 7.36 \\
\hline Girl & 5.04 & 3.76 & $-9.41^{* * *}$ & 1.71 & 1.87 & 4.43 & $-12.89^{* *}$ & 4.93 & $8.81^{* * * *}$ & 1.78 & $-31.56^{* * *}$ & 2.17 \\
\hline 6 Years Old & $-90.66^{* * *}$ & 4.78 & $-11.51^{* * *}$ & 2.32 & $-34.84^{* * *}$ & 5.50 & $22.23^{* * *}$ & 6.27 & $-55.03^{* * *}$ & 2.54 & $-103.06^{* * *}$ & 2.85 \\
\hline 8 Years Old & $-89.85^{* * *}$ & 4.98 & $-12.26^{* * *}$ & 2.42 & 6.98 & 5.74 & $24.14^{* * *}$ & 6.54 & $-52.03^{* * *}$ & 2.64 & $-85.26^{* * *}$ & 2.97 \\
\hline 10 Years Old & $-191.83^{* * *}$ & 4.90 & $-22.61^{* * *}$ & 2.38 & $-180.08^{* * *}$ & 5.65 & $-110.82^{* * *}$ & 6.43 & $-110.82^{* * *}$ & 2.60 & $-27.17^{* * *}$ & 2.92 \\
\hline 12 Years Old & $-202.56^{* * *}$ & 7.23 & $-22.36^{* * *}$ & 3.47 & $-169.31^{* * *}$ & 8.35 & $-32.26^{* * *}$ & 9.48 & $-57.24^{* * *}$ & 3.77 & $-15.50^{* * *}$ & 4.28 \\
\hline 14 Years Old & $-210.05^{* * *}$ & 7.47 & $-26.51^{* * *}$ & 3.59 & $-171.02^{* * *}$ & 8.63 & $41.17^{* * *}$ & 9.80 & $-90.20^{* * *}$ & 3.90 & $15.81^{* * *}$ & 4.43 \\
\hline Mother's College & 0.31 & 4.31 & $3.58^{+}$ & 1.98 & -8.27 & 5.06 & $11.92^{*}$ & 5.66 & $18.12^{* * *}$ & 2.08 & $-12.61^{* * *}$ & 2.50 \\
\hline Father's College & 1.76 & 4.42 & 0.49 & 2.03 & $-8.97^{+}$ & 5.19 & 1.15 & 5.80 & $13.89^{* * *}$ & 2.13 & $-10.14^{* * *}$ & 2.56 \\
\hline Mother: Manager or Professional Occupation & $-12.06^{*}$ & 6.07 & $8.27^{* *}$ & 2.91 & -10.52 & 7.03 & $30.84^{* * *}$ & 7.97 & $12.45^{* * *}$ & 3.15 & $-6.20^{+}$ & 3.59 \\
\hline Mother: Intermediate Class & -3.03 & 6.23 & -0.11 & 2.98 & 4.46 & 7.20 & $33.00^{* * *}$ & 8.17 & $8.21^{*}$ & 3.22 & $-7.33^{*}$ & 3.68 \\
\hline Mother: Not in Employment & $33.98^{* * *}$ & 5.41 & $-13.28^{* * *}$ & 2.58 & $-12.43^{*}$ & 6.27 & $29.42^{* * *}$ & 7.10 & $13.26^{* * *}$ & 2.77 & 3.29 & 3.19 \\
\hline Father: Manager or Professional Occupation & 5.52 & 5.37 & $-4.45^{+}$ & 2.56 & 4.90 & 6.22 & $31.75^{* * *}$ & 7.04 & $6.86^{*}$ & 2.76 & -0.69 & 3.17 \\
\hline Father: Intermediate Class & 4.59 & 5.87 & $-6.09^{*}$ & 2.80 & 10.08 & 6.81 & $13.41^{+}$ & 7.70 & 3.88 & 3.01 & 1.79 & 3.47 \\
\hline Father: Not in Employment & $-66.12^{* * *}$ & 8.08 & $21.45^{* * *}$ & 3.84 & $43.67^{* * *}$ & 9.37 & 9.58 & 10.60 & 4.08 & 4.14 & $20.03^{* * *}$ & 4.77 \\
\hline Resident parent re-partners & $-78.04^{* * *}$ & 16.01 & $23.69^{* *}$ & 7.64 & $67.39^{* * *}$ & 18.55 & 29.06 & 21.00 & $17.76^{*}$ & 8.22 & -13.04 & 9.45 \\
\hline Intercept & $285.02^{* * *}$ & 9.59 & $69.07^{* * *}$ & 4.49 & $256.45^{* * *}$ & 11.19 & $187.06^{* * *}$ & 12.58 & $163.22^{* * *}$ & 4.78 & $197.16^{* * *}$ & 5.61 \\
\hline Within $R^{2}$ & \multicolumn{2}{|c|}{0.18} & 0.0 & & 0 . & & 0. & & 0.1 & & 0.1 & \\
\hline Number of observations & 1486 & & 148 & & 148 & & 148 & & 148 & & 148 & \\
\hline
\end{tabular}

Source: Longitudinal Study of Australian Children. K Cohort, Waves 1 to 6, weekdays time-diaries. ${ }^{+} p<.10 * p<.05,{ }^{* *} p<.01,{ }^{* * *} p<.001$.

Note: Results from twelve separated Random-Effects GLS models. Six models estimate separation average effects -from intact to a separated family- (above) and six additional models estimate the long-term separation effects -including the years before and after separation- (below) to predict children's daily minutes. In all twelve models, the reference category of child age is "4 years old" and the reference category of both mother's class and father's class is "working-class occupation”. All models control additionally for language spoken at home and the country's region of residence. 
Table A3. Fixed-Effect Models. Children's Daily Minutes. Parental Separation Average and Long-Term Effects

\begin{tabular}{|c|c|c|c|c|c|c|c|c|c|c|c|c|}
\hline & \multicolumn{2}{|c|}{$\begin{array}{l}\text { Mother-Child } \\
\text { Solo Time }\end{array}$} & \multicolumn{2}{|c|}{$\begin{array}{l}\text { Father-Child } \\
\text { Solo Time }\end{array}$} & \multicolumn{2}{|c|}{$\begin{array}{c}\text { Two-Parents' } \\
\text { Time }\end{array}$} & \multicolumn{2}{|c|}{$\begin{array}{l}\text { Time } \\
\text { Alone }\end{array}$} & \multicolumn{2}{|c|}{$\begin{array}{c}\text { Educational } \\
\text { Activities }\end{array}$} & \multicolumn{2}{|c|}{$\begin{array}{c}\text { Unstructured } \\
\text { Activities } \\
\end{array}$} \\
\hline & $\beta$ & $S E$ & $\beta$ & $S E$ & $\beta$ & $S E$ & $\beta$ & $S E$ & $\beta$ & $S E$ & $\beta$ & $S E$ \\
\hline Separation Average Effects & $90.78^{* * *}$ & 10.28 & -6.48 & 4.95 & $-93.36^{* * *}$ & 11.71 & -3.31 & 13.24 & -8.61 & 5.40 & $21.80^{* * *}$ & 6.07 \\
\hline 6 Years old & $-91.15^{* * *}$ & 5.07 & $-9.58^{* * *}$ & 2.44 & $-34.56^{* * *}$ & 5.78 & $19.08^{* *}$ & 6.53 & $-56.64^{* * *}$ & 2.66 & $-102.74^{* * *}$ & 3.00 \\
\hline 8 Years old & $-90.07^{* * *}$ & 5.32 & $-10.57^{* * *}$ & 2.56 & 5.44 & 6.06 & $20.87^{* *}$ & 6.85 & $-54.77^{* * *}$ & 2.79 & $-86.11^{* * *}$ & 3.14 \\
\hline 10 Years old & $-192.09^{* * *}$ & 5.32 & $-20.20^{* * *}$ & 2.56 & $-179.03^{* * *}$ & 6.06 & $-113.58^{* * *}$ & 6.85 & $-112.34^{* * *}$ & 2.80 & $-29.64^{* * *}$ & 3.14 \\
\hline 12 Years old & $-207.66^{* * *}$ & 8.41 & $-24.24^{* * *}$ & 4.05 & $-166.35^{* * *}$ & 9.58 & $-30.83^{* *}$ & 10.83 & $-58.31^{* * *}$ & 4.42 & $-14.20^{* *}$ & 4.97 \\
\hline 14 Years old & $-217.34^{* * *}$ & 8.64 & $-29.64^{* * *}$ & 4.16 & $-165.70^{* * *}$ & 9.84 & $39.22^{* * *}$ & 11.12 & $-93.43^{* * *}$ & 4.53 & $18.72^{* * *}$ & 5.10 \\
\hline Mother's College & -10.79 & 13.07 & 2.27 & 6.30 & 20.00 & 14.89 & 14.71 & 16.83 & -1.32 & 6.86 & 6.39 & 7.72 \\
\hline Father's College & 19.95 & 15.72 & -8.51 & 7.57 & -10.15 & 17.90 & 15.88 & 20.23 & 7.56 & 8.25 & 10.25 & 9.28 \\
\hline Mother: Manager or Professional Occupation & -7.33 & 7.24 & 2.04 & 3.49 & $-18.45^{*}$ & 8.25 & $33.73^{* * *}$ & 9.32 & $15.57^{* * *}$ & 3.80 & -3.54 & 4.28 \\
\hline Mother: Intermediate Class & -4.34 & 7.42 & -3.63 & 3.57 & 4.85 & 8.45 & $37.68^{* * *}$ & 9.55 & $10.68^{* *}$ & 3.90 & -4.29 & 4.38 \\
\hline Mother: Not in Employment & $27.85^{* * *}$ & 6.97 & $-10.76^{* *}$ & 3.36 & $-17.61^{*}$ & 7.94 & $34.40^{* * *}$ & 8.97 & $11.15^{* *}$ & 3.66 & 2.18 & 4.11 \\
\hline Father: Manager or Professional Occupation & -1.74 & 6.70 & $-5.63^{+}$ & 3.23 & 12.02 & 7.63 & $30.56^{* * *}$ & 8.63 & 0.81 & 3.52 & 6.31 & 3.96 \\
\hline Father: Intermediate Class & -0.38 & 7.44 & $-6.67^{+}$ & 3.58 & $14.87^{+}$ & 8.48 & $20.49^{*}$ & 9.58 & 4.41 & 3.91 & 5.04 & 4.39 \\
\hline Father: Not in Employment & $-48.96^{* * *}$ & 10.68 & $17.23^{* * *}$ & 5.15 & $36.27^{* *}$ & 12.17 & $25.05^{+}$ & 13.75 & 5.37 & 5.61 & $15.06^{*}$ & 6.31 \\
\hline Resident parent re-partners & $-82.18^{* * *}$ & 19.21 & 2.72 & 9.25 & $82.24^{* * *}$ & 21.88 & $62.04^{*}$ & 24.73 & $21.07^{*}$ & 10.08 & -17.71 & 11.34 \\
\hline Intercept & $333.72^{* * *}$ & 31.42 & $60.30^{* * *}$ & 15.13 & $225.36^{* * *}$ & 35.79 & $140.59^{* * *}$ & 40.44 & $201.69^{* * *}$ & 16.49 & $153.44^{* * *}$ & 18.55 \\
\hline Within $R^{2}$ & \multicolumn{2}{|c|}{0.19} & \multicolumn{2}{|c|}{0.02} & \multicolumn{2}{|c|}{0.18} & \multicolumn{2}{|c|}{0.06} & \multicolumn{2}{|c|}{0.17} & \multicolumn{2}{|c|}{0.18} \\
\hline Number of observations & \multicolumn{2}{|c|}{14862} & \multicolumn{2}{|c|}{14862} & \multicolumn{2}{|c|}{14862} & \multicolumn{2}{|c|}{14862} & \multicolumn{2}{|c|}{14862} & \multicolumn{2}{|c|}{14862} \\
\hline$-10 /-8$ Years before Separation (ref) & & & & & & & & & & & & \\
\hline - 6/-4 Years before Separation & -23.86 & 25.01 & 14.44 & 12.06 & -45.87 & 28.53 & -10.89 & 32.25 & -17.14 & 13.16 & 9.97 & 14.80 \\
\hline - 2 Years before Separation & $-59.18^{*}$ & 26.81 & 16.02 & 12.93 & -41.50 & 30.58 & 16.13 & 34.56 & -21.03 & 14.10 & 18.26 & 15.86 \\
\hline 0 Years since Separation & $78.07^{* *}$ & 26.93 & 15.93 & 12.99 & $-152.05^{* * *}$ & 30.72 & -16.72 & 34.72 & $-24.19^{+}$ & 14.16 & $36.42^{*}$ & 15.93 \\
\hline + 2 Years after Separation & 40.27 & 28.75 & 3.76 & 13.87 & $-122.07^{* * *}$ & 32.80 & 26.33 & 37.07 & -22.62 & 15.12 & $34.53^{*}$ & 17.01 \\
\hline$+4 /+6$ Years after Separation & -29.44 & 29.46 & -10.93 & 14.21 & $-89.69^{* *}$ & 33.61 & 20.44 & 37.98 & $-33.42^{*}$ & 15.49 & $38.78^{*}$ & 17.43 \\
\hline 6 Years old & $-90.46^{* * *}$ & 5.11 & $-10.12^{* * *}$ & 2.46 & $-33.22^{* * *}$ & 5.83 & $19.30^{* *}$ & 6.58 & $-56.20^{* * *}$ & 2.69 & $-103.14^{* * *}$ & 3.02 \\
\hline 8 Years old & $-89.24^{* * *}$ & 5.36 & $-11.27^{* * *}$ & 2.59 & 7.01 & 6.12 & $20.38^{* *}$ & 6.92 & $-54.37^{* * *}$ & 2.82 & $-86.71^{* * *}$ & 3.17 \\
\hline 10 Years old & $-189.40^{* * *}$ & 5.38 & $-20.51^{* * *}$ & 2.59 & $-178.32^{* * *}$ & 6.14 & $-114.99^{* * *}$ & 6.94 & $-111.78^{* * *}$ & 2.83 & $-30.47^{* * *}$ & 3.18 \\
\hline 12 Years old & $-197.18^{* * *}$ & 8.56 & $-22.57^{* * *}$ & 4.13 & $-169.80^{* * *}$ & 9.76 & $-35.71^{* *}$ & 11.03 & $-57.00^{* * *}$ & 4.50 & $-15.32^{* *}$ & 5.06 \\
\hline 14 Years old & $-205.01^{* * *}$ & 8.82 & $-27.39^{* * *}$ & 4.25 & $-170.12^{* * *}$ & 10.06 & $34.57^{* *}$ & 11.37 & $-91.81^{* * *}$ & 4.64 & $17.51^{* * *}$ & 5.22 \\
\hline Mother's College & -9.80 & 13.05 & 2.44 & 6.29 & 19.51 & 14.89 & 14.19 & 16.83 & -1.25 & 6.86 & 6.37 & 7.72 \\
\hline Father's College & 19.55 & 15.69 & -8.80 & 7.57 & -9.52 & 17.90 & 16.20 & 20.23 & 7.63 & 8.25 & 10.18 & 9.28 \\
\hline Mother: Manager or Professional Occupation & -7.04 & 7.23 & 2.17 & 3.49 & $-19.07^{*}$ & 8.25 & $33.38^{* * *}$ & 9.32 & $15.41^{* * *}$ & 3.80 & -3.52 & 4.28 \\
\hline Mother: Intermediate Class & -3.81 & 7.41 & -3.34 & 3.57 & 4.13 & 8.45 & $37.04^{* * *}$ & 9.55 & $10.58^{* *}$ & 3.90 & -4.25 & 4.38 \\
\hline Mother: Not in Employment & $28.44^{* * *}$ & 6.95 & $-10.65^{* *}$ & 3.35 & $-17.89^{*}$ & 7.93 & $34.18^{* * *}$ & 8.97 & $11.22^{* *}$ & 3.66 & 2.09 & 4.11 \\
\hline Father: Manager or Professional Occupation & 5.56 & 6.78 & -3.91 & 3.27 & 8.74 & 7.74 & $28.03^{* *}$ & 8.75 & 1.83 & 3.57 & 6.05 & 4.01 \\
\hline Father: Intermediate Class & 5.53 & 7.48 & -5.06 & 3.61 & 11.98 & 8.54 & $18.37^{+}$ & 9.65 & 5.27 & 3.94 & 4.87 & 4.43 \\
\hline Father: Not in Employment & $-46.59^{* * *}$ & 10.67 & $17.74^{* * *}$ & 5.14 & $35.79^{* *}$ & 12.17 & $24.23^{+}$ & 13.75 & 6.00 & 5.61 & $14.95^{*}$ & 6.31 \\
\hline Resident parent re-partners & $-50.95^{* *}$ & 19.61 & 11.14 & 9.46 & $60.80^{* *}$ & 22.38 & $46.89^{+}$ & 25.29 & $21.29^{*}$ & 10.32 & -18.55 & 11.60 \\
\hline Intercept & $331.88^{* * *}$ & 31.54 & $57.12^{* * *}$ & 15.21 & $234.32^{* * *}$ & 35.98 & $144.41^{* * *}$ & 40.67 & $203.48^{* * *}$ & 16.59 & $152.16^{* * *}$ & 18.66 \\
\hline Within $R^{2}$ & \multicolumn{2}{|c|}{0.20} & \multicolumn{2}{|c|}{0.02} & \multicolumn{2}{|c|}{0.18} & 0.0 & & 0.1 & & 0.1 & \\
\hline Number of observations & 1486 & & 148 & & & & 148 & & 148 & & $148 \mathrm{c}$ & \\
\hline
\end{tabular}

Source: Longitudinal Study of Australian Children. K Cohort, Waves 1 to $6(2004-2014) .{ }^{+} p<.10{ }^{*} p<.05,{ }^{* *} p<.01,{ }^{* * *} p<.001$.

Note: Results from twelve separated Fixed-Effects GLS models. Six models estimate separation average effects -from intact to a separated family- (above) and six additional models estimate the long-term separation effects -including the years before and after separation- (below) to predict children's daily minutes. In all twelve models, the reference category of child age is " 4 years old" and the reference category of both mother's class and father's class is "working-class occupation". All models control additionally for language spoken at home and the country's region of residence. 
Table A4. Random-Effects Regression Models of Child Time Use, interactions with Child Gender

\begin{tabular}{|c|c|c|c|c|c|c|c|c|c|c|c|c|}
\hline \multirow[b]{2}{*}{ Panel A: Average Effects } & \multicolumn{2}{|c|}{$\begin{array}{l}\text { Mother-Child } \\
\text { Solo Time }\end{array}$} & \multicolumn{2}{|c|}{$\begin{array}{l}\text { Father-Child } \\
\text { Solo Time }\end{array}$} & \multicolumn{2}{|c|}{$\begin{array}{c}\text { Two-Parents' } \\
\text { Time }\end{array}$} & \multicolumn{2}{|c|}{$\begin{array}{l}\text { Time } \\
\text { Alone }\end{array}$} & \multicolumn{2}{|c|}{$\begin{array}{c}\text { Educational } \\
\text { Activities }\end{array}$} & \multicolumn{2}{|c|}{$\begin{array}{c}\text { Unstructured } \\
\text { Activities }\end{array}$} \\
\hline & $\beta$ & $S E$ & $\beta$ & $S E$ & $\beta$ & $S E$ & $\beta$ & $S E$ & $\beta$ & $S E$ & $\beta$ & $S E$ \\
\hline \multicolumn{13}{|l|}{ Boys } \\
\hline Separation & $105.72^{* * *}$ & 11.65 & -9.28 & 5.72 & $-103.53^{* * *}$ & 13.37 & -2.13 & 15.16 & $-9.78^{+}$ & 5.73 & $24.05^{* * *}$ & 7.07 \\
\hline Intercept & $296.68^{* * *}$ & 13.55 & $66.79^{* * *}$ & 6.53 & $244.02^{* * *}$ & 15.62 & $168.98^{* * *}$ & 17.61 & $154.85^{* * *}$ & 6.49 & $197.90^{* * *}$ & 8.09 \\
\hline Controls & \multicolumn{2}{|c|}{ YES } & \multicolumn{2}{|c|}{ YES } & \multicolumn{2}{|c|}{ YES } & \multicolumn{2}{|c|}{ YES } & \multicolumn{2}{|c|}{ YES } & \multicolumn{2}{|c|}{ YES } \\
\hline Within $R^{2}$ & \multirow{2}{*}{\multicolumn{2}{|c|}{$\begin{array}{c}0.20 \\
7476\end{array}$}} & \multirow{2}{*}{\multicolumn{2}{|c|}{$\begin{array}{c}0.01 \\
7476\end{array}$}} & & & \multirow{2}{*}{\multicolumn{2}{|c|}{$\begin{array}{c}0.07 \\
7476\end{array}$}} & \multirow{2}{*}{\multicolumn{2}{|c|}{$\begin{array}{l}0.18 \\
7476\end{array}$}} & \multirow{2}{*}{\multicolumn{2}{|c|}{$\begin{array}{c}0.20 \\
7476\end{array}$}} \\
\hline Number of observations & & & & & \multicolumn{2}{|c|}{$\begin{array}{l}0.17 \\
7476\end{array}$} & & & & & & \\
\hline \multicolumn{13}{|l|}{ Girls } \\
\hline Separation & $105.36^{* * *}$ & 10.60 & -1.92 & 4.83 & $-90.54^{* * *}$ & 12.49 & $-24.14^{+}$ & 14.05 & -6.01 & 5.57 & $11.75^{*}$ & 5.98 \\
\hline Intercept & $284.66^{* * *}$ & 12.90 & $64.76^{* * *}$ & 5.87 & $268.96^{* * *}$ & 15.32 & $186.00^{* * *}$ & 17.16 & $180.13^{* * *}$ & 6.75 & $166.28^{* * *}$ & 7.34 \\
\hline Controls & \multicolumn{2}{|c|}{ YES } & \multicolumn{2}{|c|}{ YES } & \multicolumn{2}{|c|}{ YES } & \multicolumn{2}{|c|}{ YES } & \multicolumn{2}{|c|}{ YES } & \multicolumn{2}{|c|}{ YES } \\
\hline Within $R^{2}$ & $0.1-1$ & & & & & & $0 .($ & & 0 . & & 0.1 & \\
\hline Number of observations & 73 & & & & & & 73 & & 73 & & 738 & \\
\hline Panel B: Long-term Effects & $\beta$ & $S E$ & $\beta$ & $S E$ & $\beta$ & $S E$ & $\beta$ & $S E$ & $\beta$ & $S E$ & $\beta$ & $S E$ \\
\hline Years before / after separation & & & & & & & & & & & & \\
\hline$-6 /-4$ & $31.75^{* *}$ & 11.14 & -1.01 & 5.22 & -10.05 & 12.83 & $-43.55^{* *}$ & 14.46 & -5.00 & 5.54 & -3.77 & 6.47 \\
\hline-2 & 11.00 & 15.25 & 1.02 & 7.27 & $33.87^{+}$ & 17.55 & -12.36 & 19.88 & -9.09 & 7.83 & 2.80 & 8.96 \\
\hline 0 & $142.18^{* * *}$ & 14.24 & -1.67 & 6.77 & $-125.41^{* * *}$ & 16.39 & $-33.11^{+}$ & 18.56 & -11.55 & 7.29 & $26.39^{* *}$ & 8.35 \\
\hline+2 & $104.61^{* * *}$ & 17.29 & -0.76 & 8.25 & $-78.97^{* * *}$ & 19.89 & -13.23 & 22.54 & -10.68 & 8.89 & $36.85^{* * *}$ & 10.16 \\
\hline$+4 /+6$ & $60.22^{* * * *}$ & 17.64 & $-21.35^{*}$ & 8.36 & $-59.34^{* *}$ & 20.31 & -13.39 & 22.97 & -11.47 & 8.95 & $24.75^{*}$ & 10.32 \\
\hline Girls & $7.35^{+}$ & 4.11 & $-10.39^{* * *}$ & 1.87 & 3.05 & 4.75 & $-15.59^{* *}$ & 5.30 & $8.06^{* * *}$ & 1.92 & $-31.22^{* * *}$ & 2.34 \\
\hline Years before / after separation & & & & & & & & & & & & \\
\hline$-6 /-4$ & $-33.25^{*}$ & 15.42 & $13.85^{+}$ & 7.23 & 15.42 & 17.76 & $36.96^{+}$ & 20.02 & 4.18 & 7.68 & 10.42 & 8.96 \\
\hline-2 & -33.61 & 20.77 & 14.59 & 9.90 & $-71.25^{* *}$ & 23.90 & 20.28 & 27.08 & 7.87 & 10.66 & 10.19 & 12.20 \\
\hline 0 & -11.31 & 19.51 & 13.23 & 9.28 & 6.00 & 22.45 & -28.87 & 25.42 & 3.82 & 9.98 & -12.64 & 11.44 \\
\hline+2 & 1.70 & 23.44 & -11.93 & 11.19 & -14.49 & 26.97 & 24.84 & 30.57 & 8.32 & 12.06 & $-41.07^{* *}$ & 13.78 \\
\hline$+4 /+6$ & -14.99 & 22.87 & 7.39 & 10.83 & -15.99 & 26.33 & 27.26 & 29.77 & 1.33 & 11.59 & -10.49 & 13.38 \\
\hline Intercept & $293.03^{* * *}$ & 7.76 & $63.75^{* * *}$ & 3.58 & $258.69^{* * *}$ & 8.95 & $234.45^{* * *}$ & 10.04 & $178.80^{* * *}$ & 3.74 & $198.22^{* * *}$ & 4.46 \\
\hline Controls & $\mathrm{YE}$ & & $\mathrm{Y}$ & & & & $\mathrm{YI}$ & & $\mathrm{Y}$ & & $\mathrm{YE}$ & \\
\hline Within $R^{2}$ & 0.1 & & 0. & & & & 0. & & 0. & & 0.1 & \\
\hline Number of observations & 148 & & 14 & & & & 148 & & 14 & & 148 & \\
\hline
\end{tabular}

Source: Longitudinal Study of Australian Children. K Cohort, Waves 1 to $6(2002-2014) . \quad{ }^{+} p<.10{ }^{*} p<.05, * * p<.01, * * * p<.001$.

Note: Panel A shows regression estimated separately in two subsamples of girls and boys (i.e., twelve regressions, six per sex). Panel B shows six regressions where each of them includes an interaction term between child's sex and separation in a categorical form that indexes years before and after. All models control for child sex, child age, maternal education, paternal education, mother's class, father's class, language spoken at home, number of siblings, region of residence, and residential parent re-partnering. Confidence Intervals are included at the $95 \%$ level $(\mathrm{Number}$ of observations $=14,862)$. 